\title{
Thermodynamic analysis and optimisation of a combined liquid air and pumped thermal energy storage cycle
}

\author{
Pau Farres-Antunez*, Haobai Xue and Alexander J. White \\ Department of Engineering, University of Cambridge, United Kingdom \\ *Corresponding author:pf298@cam.ac.uk
}

\begin{abstract}
Pumped thermal energy storage (PTES) and liquid air energy storage (LAES) are two large-scale electricity storage technologies that store energy in the form of thermal exergy. This is achieved by operating mechanicallydriven thermodynamic cycles between thermally insulated storage tanks. Both technologies are free from geographic restrictions that apply to pumped hydro and most compressed air storage. The present paper describes a novel, combined system in which PTES operates as a topping cycle and LAES as a bottoming cycle. The fundamental advantage is that the cold thermal reservoirs that would be required by the two separate cycles are replaced by a single heat exchanger that acts between them, thereby saving significant amounts of storage media per unit of energy stored. In order to reach cryogenic temperatures, the PTES cycle employs helium as the working fluid, while the LAES cycle uses supercritical air (at around 150 bar) which is cooled sufficiently to be fully liquefied upon expansion, thus avoiding recirculation of leftover vapour. A thermodynamic study of a baseline configuration of the combined cycle is presented and results are compared with those of the separate systems. These indicate that the new cycle has a similar round-trip efficiency to that of the separate systems while providing a significantly larger energy density. Furthermore, three adaptations of the base-case combined cycle are proposed and optimised. The best of these adaptations achieves an increase in thermodynamic efficiency of about 10 percent points (from $60 \%$ to $70 \%$ ), therefore significantly exceeding the individual cycles in both energy density and efficiency.
\end{abstract}

\section{Introduction}

Growing amounts of renewable energy generation are being deployed worldwide in an effort to reduce greenhouse emissions and improve long-term security of the energy supply $[1,2]$. While the fluctuating nature of wind and solar energy poses a challenge to balancing production and demand in the power network, it is now wellestablished that large-scale storage can significantly contribute to mitigating the effects of such fluctuations $[3,4]$.

Pumped thermal energy storage (PTES) and liquid air energy storage (LAES) are two relatively new technologies that can potentially operate on a large scale. They use mechanically-driven thermodynamic cycles to store electricity in the form of high-grade (hot and cold) thermal exergy [5]. Both technologies use abundant materials and are geographically unconstrained, providing a significant advantage over competing methods such as pumped hydro or compressed air storage. Round-trip efficiencies for PTES and LAES are limited mainly by irreversibilities in the form of compression, expansion and heat exchange losses and so ongoing research is focused on reducing such losses through optimisation of components and of the cycle operating conditions.

Following a brief review of PTES and LAES, section 2 of this paper presents the new combined cycle. The thermodynamic model and underlying assumptions are then described in section 3, while section 4 presents the results and a comparison with separate PTES and LAES models based on the same assumptions. Finally, section 5 proposes three variations of the combined cycle which aim at further increasing its efficiency. Since two of these variations introduce new degrees of freedom, a multi-variable optimisation routine is employed to maximise performance within the cycle constraints.

\subsection{PTES review}

Pumped thermal energy storage employs an electrically-driven heat pump to transfer thermal energy from a cold to a hot reservoir. Energy is therefore stored in the form of a thermal potential. During discharge, a heat engine is operated between the same reservoirs in order to recover the energy stored. One of the main motivations behind such schemes is that thermal storage materials provide high storage densities, are cheap and abundant and thus well suited for large-scale applications. The technology has received growing attention during the last decade, with a number of research groups proposing different cycles with the same basic principle. Thermal energy may be stored in the form of sensible heat (with several candidate storage materials), or latent heat (typically using phasechange materials - PCMs). The environment may also be employed as a heat source or sink. Joule-Brayton-based systems using Argon as the working fluid have been proposed by Desrue et al. [6] (using turbomachinery) and 
Howes [7] (using reciprocating devices), both using solid storage media. One of the potential advantages of the latter system is that the same devices may be used as both compressors and expanders by adjusting valve timings, thereby saving on the total number of components and allowing faster reversal between charge and discharge. Simple cycle analysis of Joule-Brayton-based systems (e.g., [8]) shows that they are particularly susceptible to compression and expansion losses, but this may be mitigated by increasing the work ratio, usually at the expense of higher temperature (and hence more challenging) operating conditions. Other cycles that have inherently higher work ratios have been proposed, such as supercritical $\mathrm{CO}_{2}$ cycles (e.g., $[9,10]$ by Mercangoz and Morandin et al.) and a steam Rankine cycle $([11,5]$ by Steinmann). The former operate over low temperature ratios, which have the disadvantage of a low energy density and a higher impact of heat-exchange losses, but allow the use of cheap storage media such as hot water and salt-water ice slurry. The steam-based cycle employs higher temperature ratios and makes use of conventional Rankine cycle technology, although it relies on latent heat storage units (consisting of PCMs with embedded heat exchangers) that prevent an independent sizing of power and energy capacity. However, alternative PCM pumping strategies which have the potential to overcome this drawback are currently being investigated $[12,13]$.

Many variations have been proposed to the above-described cycles. For example, the Joule-Brayton-based cycles may use liquid storage media and gas-to-liquid heat exchangers instead of solid (direct heat exchange) reservoirs, as previously proposed by the authors of the present work [14, 15]. Doing so allows the gas circuit to be pressurised (thereby increasing power density) whilst keeping the reservoirs at ambient pressure (thereby reducing cost per $\mathrm{kWh}$ storage relative to pressurised packed-beds). Each storage tank is also kept at a single temperature, thus avoiding thermal equilibration (mixing) losses during long storage periods. A regenerative heat exchanger may also be incorporated into the cycle in order to adapt cycle temperatures to suit different storage media, which must remain liquid. An example of this is shown in Fig. 1a where propane is being used as the cold storage medium and must be kept below its boiling point of $\sim 230 \mathrm{~K}$. Regeneration also has benefits in terms of efficiency and energy and power density, as it increases the work-ratio. Further details of regenerative PTES, including an assessment of thermodynamic, economic and safety aspects, are given in a recent paper by Laughlin [16].

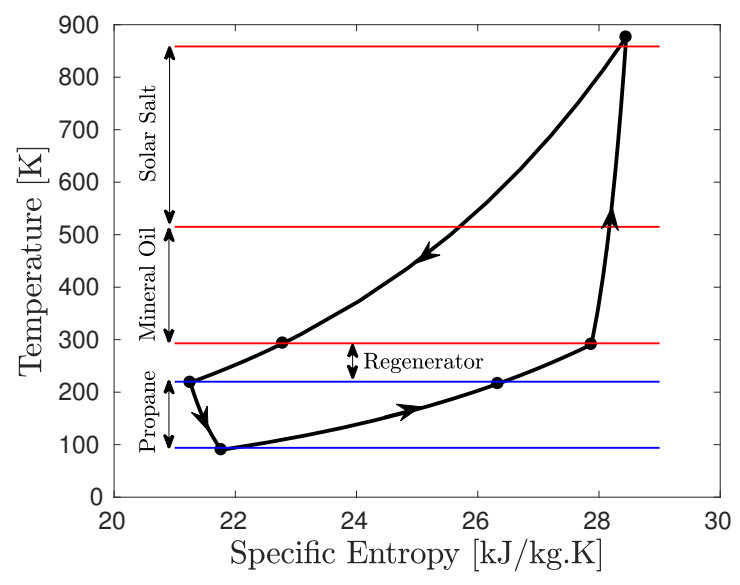

(a) Joule-Brayton-based PTES

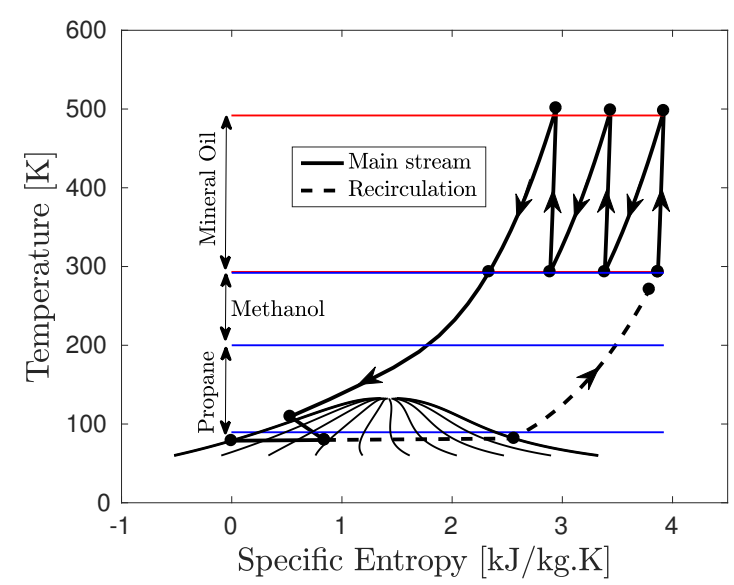

(b) Linde-based LAES with cold recycling.

Figure 1: T-s diagrams of representative PTES and LAES cycles, shown during charge: (a) Joule-Brayton-based PTES system using molten salts and mineral oil as hot storage media and propane for cold storage. A gas-gas heat exchanger (regenerator) is also employed. (b) LAES system based on an adaptation of the Linde cycle which uses cold recycling between discharge and charge. While the hot TES consists of mineral oil, methanol and propane are used as cold storage media, similarly to [17].

\subsection{LAES review}

Liquid Air Energy Storage (LAES), as the name suggests, involves liquefying air so that it can be stored at nearambient pressure in insulated tanks. One possible implementation, shown in Figure 1b, resembles the Linde cycle with the addition of 'cold recycling', as described below. During charge, air is first compressed (using off-peak electricity) in several intercooled stages, meanwhile transferring heat to thermal energy stores (TESs). The compressed air is further cooled via a cold TES which has been pre-charged during the discharge phase of the previous cycle. This is the 'cold recycling' process, which is essential for achieving acceptable round-trip 
efficiencies [18]. In the example shown it is implemented via tanks of liquid methanol and propane, similarly to the scheme in [17], but other storage media are also possible. The final process during charge is expansion of the cold compressed air back to ambient pressure through a throttle or a cryo-expander. The resulting twophase mixture is separated with the 'flash gas' being recirculated (dashed line in the figure) whilst the liquid air is transferred to cryogenic tanks. During discharge the liquid air is pumped back up to high pressure, heated by passing through the cold TES (thereby recharging it) and then further heated in the hot TES. Finally it is expanded through turbines (with intermediate TES reheat) to generate electricity.

The concept of LAES was first proposed by Smith in 1977 [19] but later developed by both academic and industrial groups, the latter including Mitsubishi [20], Hitachi [21] and Highview [18]. Early this century, an integrated LAES and gas turbine (GT) system was proposed to reduce the GT compression work by compressing liquid rather than ambient air. The liquid air in this case was obtained via the Linde process (exploiting off-peak electricity), and the power output of the GT was more than doubled relative to that of a conventional cycle [20, 21].

A key milestone for LAES was the completion and testing of a $350 \mathrm{~kW} / 2.5 \mathrm{MWh}$ demonstration plant by Highview, based on the Claude liquefaction cycle (charge) and the Rankine cycle (discharge) [18]. During discharge, some of the exergetic content of the liquid air is stored by cooling a quartz-based packed bed for later use during the next charge. The measured round-trip efficiency was only $8 \%$ but it is expected that larger-scale plants and process improvements will enable efficiencies above $50 \%$ to be attained [18, 22].

Ongoing research activity in LAES includes analyses of systems exploiting liquid TES [17, 23], pinch point analysis, parametric studies, and integration with both nuclear and renewable generation [24, 25]. Finally, a hybrid CAES / LAES system has also been proposed that combines the low cost of LAES with the relatively high efficiency of CAES to maximise profits in energy markets where storage is required at different time-scales [26].

\section{The combined cycle}

\subsection{Motivation}

One of the appeals of LAES is its ostensibly high available energy density: the maximum work that can in principle be extracted from liquid air in returning it to ambient conditions is roughly $170 \mathrm{kWh} \mathrm{m}^{-3}$ (this compares with $16-26 \mathrm{kWh} \mathrm{m}^{-3}$ for compressed air stored at pressures of 120-180 bar). However, a significant fraction of this is required during discharge for the cold recycling process, as described above. To highlight this point, Table 1 shows the specific exergy of air ( $e=b-b_{0}$ where $b$ is the steady flow availability function and subscript 0 denotes the dead state) at typical conditions for various points in an LAES plant. It is striking that roughly half the initial exergetic content of the liquid air is removed in charging the cold store, which, when combined with the additional space requirements of the cold TES itself, leads to a very much lower storage density than might originally be expected. This provides the motivation for the proposed combined cycle: rather than storing 'cold exergy' during discharge, the additional cooling required prior to liquefaction is provided by the cold side of a PTES topping cycle. There is therefore no need for a cold TES for either the LAES or for the PTES plant, and, crucially, these two cycles operate in the same direction (i.e., they are both either charging or discharging together).

Table 1: Flow exergy of air at different points of a LAES cycle. $T_{0}=290 \mathrm{~K}$ and $p_{0}=1 \mathrm{bar}$.

\begin{tabular}{|c|c|c|c|c|}
\hline Location (discharge) & State & Temperature [K] & Pressure [bar] & Exergy [Wh/kg] \\
\hline \hline Cryogenic tank & Liquid air & 78.8 & 1 & 195.2 \\
\hline Pump outlet & Supercritical, cryogenic & 82 & 100 & 197.1 \\
\hline Cold TES outlet & Supercritical, ambient & 290 & 100 & 105.9 \\
\hline
\end{tabular}

\subsection{Concept and layout}

The layout of the proposed combined cycle is shown in Fig. 2, together with representative T-s diagrams of the two sub-systems. Helium is assumed as the working fluid for the PTES cycle in the present analysis because it is one of the few substances that remains gaseous at air-liquefaction temperatures. Furthermore, it is cheap and has good heat transfer vs. pressure loss characteristics relative to alternatives. (On the other hand, due to its low molecular weight, many compression stages are required to achieve a sufficient pressure ratio or temperature rise when using traditional turbomachinery. In this respect, neon may prove a better choice once full costing is undertaken.) Both the LAES and PTES cycles are assumed to start at ambient temperature and pressure at point 1, though, again for reasons of cost, it may in practice be beneficial to pressurise the PTES system. Both flows enter a compression process followed by cooling, where the working fluids transfer heat to the storage media. In this study, the storage media is assumed to be liquid and heat transfer occurs in counter-flow heat exchangers, but schemes using solid 
storage with direct heat exchange (e.g., packed beds) are also possible. Since the counter-flow heat exchangers are not perfectly effective, additional low-cost (e.g., cross-flow) heat exchangers are used to bring the working fluids closer to ambient temperature. Compression and cooling are repeated (once for helium, twice for air), reaching the top pressures of 135 bar (helium) and 150 bar (air) for the case shown. The helium then undergoes a single expansion back to ambient pressure before entering the 'coupler', which is the main counter-flow heat exchanger linking the two cycles and which cools the supercritical air down to cryogenic temperatures. Finally, the air flows through a cryo-expander (rather than a throttle), resulting in a $100 \%$ liquid air yield at point 9 . The liquid air is then stored at ambient pressure, while the helium returns to the starting point of the closed cycle. During discharge, all processes are reversed.

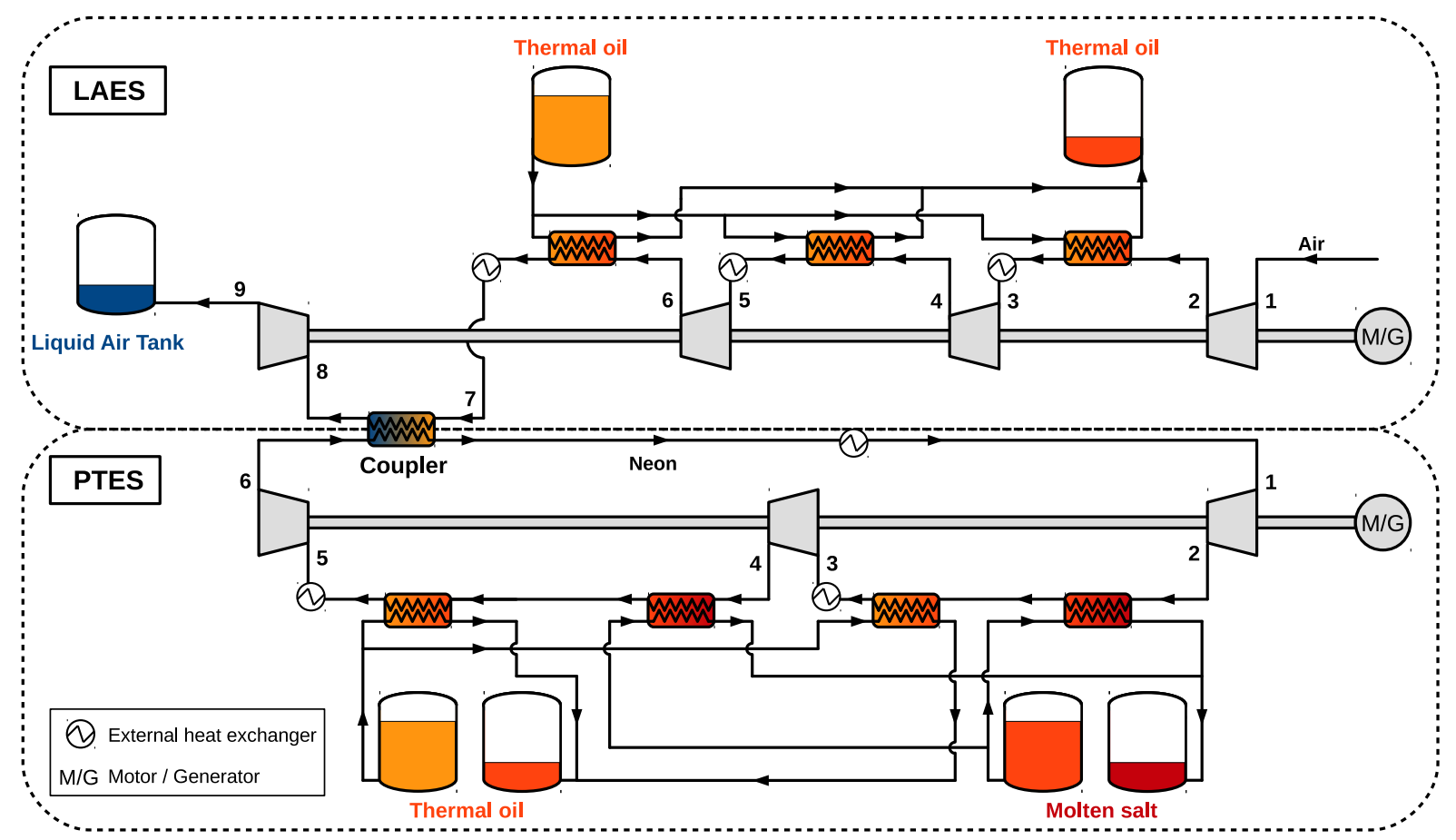

(a) Combined cycle plant layout.

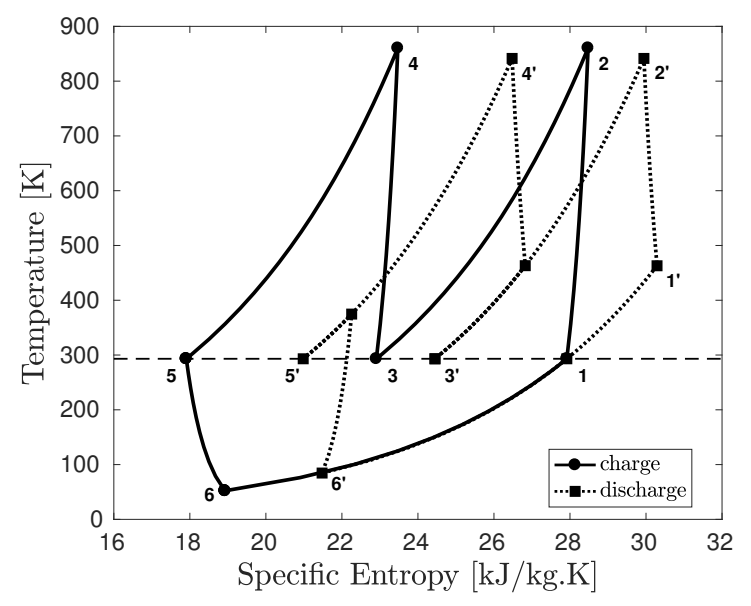

(b) T-s diagram of the PTES sub-system.

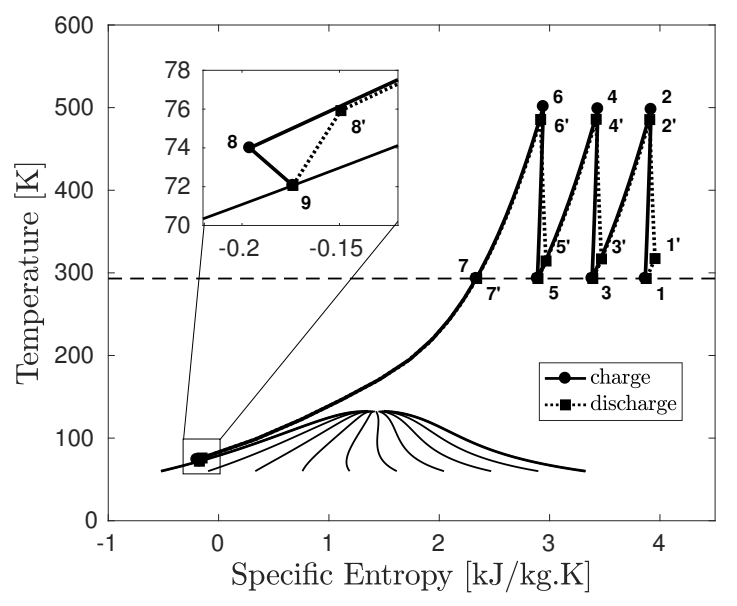

(c) T-s diagram of the LAES sub-system.

Figure 2: Proposed plant layout and T-s diagrams of the PTES and LAES sub-cycles. Arrow directions refer to charge. Primes $\left({ }^{\prime}\right)$ refer to conditions during discharge.

The combined cycle has two important features that distinguish it from the separate cycles. Firstly, the cold thermal reservoirs of the two systems have been replaced by a single heat exchanger, thus economising significantly on storage media. Secondly, the supercritical air can be cooled to temperatures that are low enough for it to be fully liquefied upon expansion. This affords several advantages, including: (a) a mechanical expansion device is more readily employed (because the damage associated with two-phase flow has been eliminated), thereby 
avoiding the significant irreversibility associated with throttling; (b) there is no need for a flash gas recirculation system and (c) the same quantity of air is processed during discharge and charge, thus providing better heat integration with the thermal stores.

It should be pointed out that the present study does not constitute the first proposal for a combined PTESLAES system. Notably, several possibilities for integrating the two cycles are described in a patent by Isentropic Ltd [27]. These are, however, quite different concepts to that considered here - for example, most are based on sub-critical LAES with a variable-pressure liquid air tank containing "ballast air"; one cycle is supercritical but it does not provide full liquefaction and is devised to work in conjunction with a combustion gas turbine.

\subsection{Storage media}

Sensible heat storage can be achieved with either solid or liquid media. Solid stores will normally be in the form of packed beds with direct heat transfer between the working fluid and the solid particles. For systems operating at high pressures, however, the packed-bed containment vessel becomes very expensive. Alternatives include the use a heat exchanger embedded within a solid block [28] or a packed bed with indirect heat transfer, employing a secondary heat exchange fluid [29]. For the first of these, the heat exchanger size is linked to the energy (rather than power) capacity, such that it is likely to be prohibitively expensive for systems with long discharge duration. The second approach may well prove cost effective, but would introduce additional heat exchange and pressure losses. Liquid thermal storage can be realised with a simple two-tank scheme (or even a single tank with a movable piston-like partition), providing effiicent and simple operation compared with the management of thermal fronts within packed beds. Liquid tanks are the current standard in most CSP plants [30] and this approach has been adopted here. The best option for thermal storage does, however, require a full cost analysis, which has yet to be undertaken for the systems currently being considered.

Table 2 shows a brief list of candidate liquids for thermal storage applications. The values of specific exergy have been computed using:

$$
\Delta e=h_{2}-h_{1}-T_{0}\left(s_{2}-s_{1}\right) \simeq c_{p}\left[T_{2}-T_{1}-T_{0} \ln \left(T_{2} / T_{1}\right)\right]
$$

where the subscripts 1 and 2 refer to discharged and charged conditions respectively and the right hand approximation is based on averaged isobaric heat capacities. $T_{0}$ is taken as $290 \mathrm{~K}$, whilst $T_{1}$ and $T_{2}$ are set to the values of $T_{\min }$ and $T_{\max }$ specified in the table, except when the fluid freezes below $T_{0}$ or when $T_{\max }$ exceeds $600^{\circ} \mathrm{C}$, in which case these limits are used instead. (The upper temperature corresponds to an approximate mechanical limit applicable to the most common alloys employed to build tanks, heat exchangers and pipes, as discussed in [16].) Material costs are taken from the specified references, except for sunflower oil and mineral oil. In the case of sunflower oil, the value was obtained by averaging bulk prices available online. In the case of mineral oil, a value of $0.3 \$ / \mathrm{kg}$ is referenced in $[31,32]$ but recent quotes from Chinese providers seem to indicate an actual cost above $1.0 \$ / \mathrm{kg}$. These cost values should, therefore, be taken with caution.

Table 2: Selection of liquid materials for sensible thermal energy storage, collected from sources: $[31,32,33,34$, $35,36,37,38]$. Specific heat capacity and density are average values. Exergy and cost per unit exergy are not from the specified sources but have been computed here. Cost values to be taken with caution.

\begin{tabular}{|l|r|c|c|c|c|c|c|}
\hline $\begin{array}{l}\text { Storage } \\
\text { medium }\end{array}$ & $\begin{array}{c}\mathrm{T}_{\min } \\
{\left[{ }^{\circ} \mathrm{C}\right]}\end{array}$ & $\begin{array}{c}\mathrm{T}_{\max } \\
{\left[{ }^{\circ} \mathrm{C}\right]}\end{array}$ & $\begin{array}{c}\text { Heat capacity } \\
{[\mathrm{kJ} / \mathrm{kg} / \mathrm{K}]}\end{array}$ & $\begin{array}{c}\text { Density } \\
{\left[\mathrm{kg} / \mathrm{m}^{3}\right]}\end{array}$ & $\begin{array}{c}\text { Cost } \\
{[\$ / \mathrm{kg}]}\end{array}$ & $\begin{array}{c}\text { Exergy } \\
{[\mathrm{Wh} / \mathrm{kg}]}\end{array}$ & $\begin{array}{c}\text { Cost/exergy } \\
{[\$ / \mathrm{kWh}]}\end{array}$ \\
\hline \hline Water & 0 & 100 & 4.2 & 980 & $\sim 0.0$ & 11.7 & $\sim 0.0$ \\
\hline Sunflower oil & -17 & 250 & 2.4 & 850 & 0.3 & 41.3 & 7.3 \\
\hline Mineral oil & -20 & 300 & 2.6 & 770 & 1.0 & 61.8 & 16.2 \\
\hline Hitec XL & 120 & 500 & 1.45 & 1990 & 1.1 & 74.0 & 14.9 \\
\hline Solar Salt & 220 & 600 & 1.55 & 1900 & 0.5 & 92.3 & 5.4 \\
\hline Na-K eutectic & -12 & 785 & 0.87 & 800 & 2.0 & 63.7 & 31.4 \\
\hline $\mathrm{Na}$ & 98 & 883 & 1.25 & 850 & 2.0 & 88.1 & 22.7 \\
\hline
\end{tabular}

For low and medium temperature storage, water and mineral oil are the most commonly used media. There seems to be little or no experience using vegetable oils for large-scale sensible heat storage, but the thermal properties of refined sunflower oil (and other vegetable oils) are promising and they could offer an alternative to mineral oil for medium temperature applications if their resistance to thermal cycling and long-term degradation proved sufficient. There are also oils from other sources, such as synthesized oil or silicone oil (not included in the table), which can reach temperatures of up to $400^{\circ} \mathrm{C}$, but their specific costs are significantly higher than that of mineral oil [32]. Additionally, synthesized oil has a vapour pressure of around $10 \mathrm{bar}$ at $390^{\circ} \mathrm{C}$ [30], meaning 


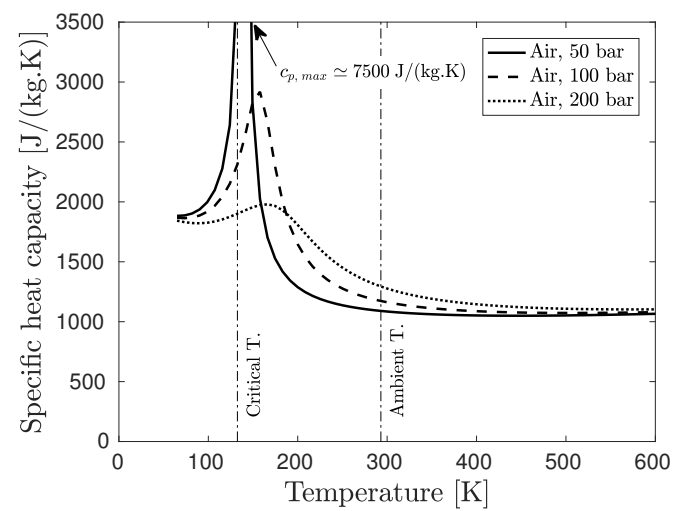

Figure 3: Specific heat capacity of supercritical air at three pressure levels.

that pressurised tanks would be required. Above $300^{\circ} \mathrm{C}$ molten salts are the most commonly used materials. While there are many molten salt formulations, only two common salts have been included here. Solar Salt is a binary mixture $\left(60 \mathrm{wt} \% \mathrm{NaNO}_{3}\right.$ and $\left.40 \mathrm{wt} \% \mathrm{KNO}_{3}\right)$ that is very often used in the concentrated solar power (CSP) industry, while Hitec XL (a ternary formulation including $\mathrm{Ca}\left(\mathrm{NO}_{3}\right)_{2}$ ) has the advantage of achieving lower melting point but at higher specific cost. For high temperatures liquid metals are also suitable (but expensive), of which only eutectic sodium / potassium mixture is able to span the full temperature range required for the hot TES of the present application. Two or more materials can of course be used in series and a combination of mineral oil and Solar Salt has been adopted for the purpose of this study. However, it is important to keep in mind that an oil storage system may have a larger footprint due to safety requirements (for example, oil tanks would need to be kept a certain distance from the molten salt stores). Other combinations are also possible and ultimately a full cost-efficiency optimisation is required.

\subsection{Coupling and operation}

One difficulty encountered when coupling the LAES and PTES subsystems is that the $c_{p}$ of helium is essentially constant whilst that of supercritical air varies significantly as it approaches its critical temperature $(132.5 \mathrm{~K})$. As shown in Fig. 3, this effect is most pronounced at pressures just above the critical pressure (37.9 bar) but becomes less so as the pressure increases. The different $c_{p}$ variations give rise to pinch points in the air-helium heat exchanger (as shown in Fig. 4) which limits cycle performance. There is an optimal mass flow ratio which lies close to that given by

$$
\left.\frac{\dot{m}_{\text {air }}}{\dot{m}_{H e}}\right|_{\text {opt }} \simeq \frac{{\overline{c_{p}}}_{H e}}{\overline{\bar{c}_{\text {air }}}}
$$

The pressure ratios of the two sub-cycles are also interlinked because the PTES pressure ratio determines the helium inlet temperature to the coupler whereas that of the LAES cycle affects the shape of the air $c_{p}$ curve, which in turn influences the air temperature at exit from the coupler. Thus, for a specified liquid air temperature, the charge pressure ratio of the PTES cycle becomes a function of the pressure ratio of the LAES cycle, as will be seen later in section 4.

The optimal discharge pressure ratio of the LAES cycle is found to be very similar to that during charge and these are therefore taken as equal in the present study. For the PTES cycle, however, the optimal pressure ratio is significantly lower during discharge. This is chiefly due to the above-mentioned pinch point issues which mean that prior to compression during discharge (point 6' on the PTES T-s diagram) the helium is considerably hotter than at the corresponding point in the charge cycle (point 6). The temperature at this point is important as it has a strong influence on the compression work. In the results that follow, the PTES discharge cycle is always operated at its optimal pressure ratio (based on round-trip efficiency) which is found by iteration.

\section{Modelling}

Straightforward 'design point' cycle calculations have been undertaken using fixed values of component performance parameters such as compression and expansion efficiencies, fractional pressure losses and heat exchanger effectiveness, as detailed below. 


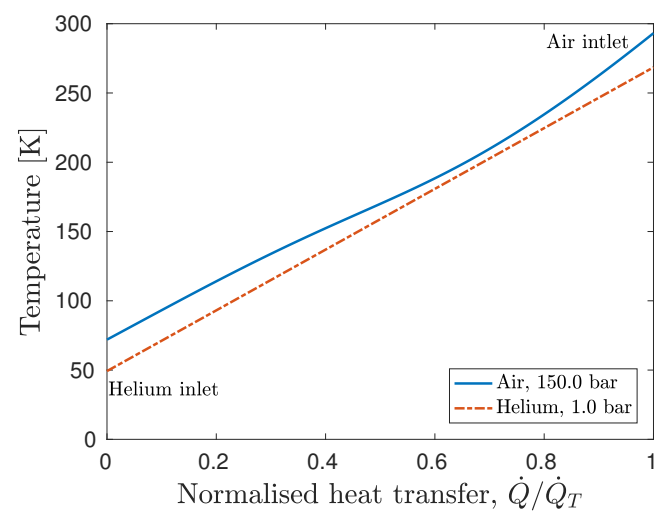

(a)

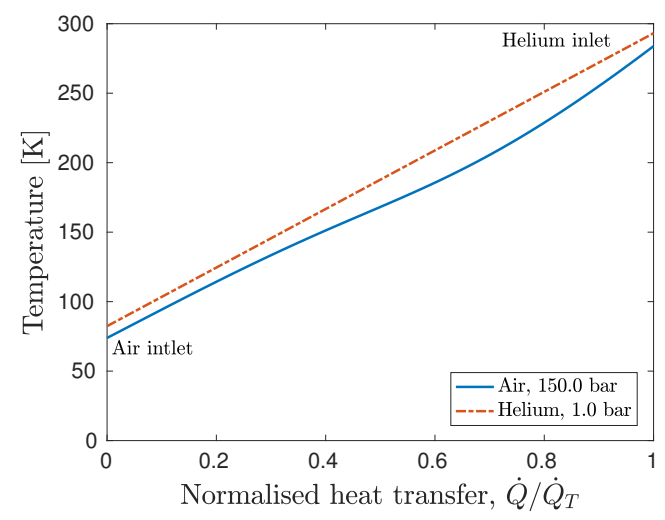

(b)

Figure 4: Temperature distribution inside the coupler during charge (a) and during discharge (b).

\subsection{Compressors and expanders}

In order to ensure a valid comparison when studying the effect of different pressure ratios on the overall performance, compressors and expanders are modelled by a polytropic (rather than isentropic) efficiency [39]. This is defined in the usual fashion as an infinitesimal stage efficiency. Thus:

$$
\begin{aligned}
\eta_{c} & \equiv \frac{\delta w_{c, r e v}}{\delta w_{c}}=\frac{v \mathrm{~d} p}{\mathrm{~d} h} \\
\eta_{e} & \equiv \frac{\delta w_{e}}{\delta w_{e, r e v}}=\frac{\mathrm{d} h}{v \mathrm{~d} p}
\end{aligned}
$$

These expressions are then integrated at constant efficiency to obtain the total change in enthalpy for specified inlet conditions and outlet pressure. For baseline calculations, $\eta_{e}=\eta_{c}=0.9$, but the effect of higher and lower values is also considered. A $90 \%$ efficiency is realistic for state-of-the-art turbomachinery, but may be an overestimate for the cryo-expander (see [40], in which a value of $88 \%$ is reported for cryogenic liquid expanders in the context of LNG). However, the corresponding work term is very small (as is the pump work during discharge) and so small changes in efficiency have little bearing. Note also that future generations of reciprocating devices might be able to offer higher efficiencies than turbomachinery for gas compression/expansion, but this is as yet unproven. (See for example $[41,7]$.)

\subsection{Heat exchangers}

The effectiveness of a heat exchanger is defined as [42]:

$$
\varepsilon=\frac{\dot{Q}}{\dot{Q}_{\max }}
$$

where $\dot{Q}_{\max }$ represents the maximum possible heat transfer rate, i.e. that of an infinitely large heat exchanger. It is worth noting that for a heat exchanger in which the two flows have equal averaged heat capacity rates (i.e., a balanced heat exchanger), but for which the fluids exhibit variations in $c_{p}$, setting $\varepsilon=1$ gives zero temperature difference at the pinch point only and not elsewhere. Heat exchange thus remains an irreversible process, even in the limit of infinite heat transfer surface. In the present study $\dot{Q}_{\max }$ is first determined by imposing zero temperature difference at the pinch point for given mass flows and inlet conditions, and the actual heat transfer rate $\dot{Q}$ is then found by applying the selected level of effectiveness. Baseline calculations assume $97 \%$ effectiveness, but $\varepsilon$ is also varied to assess its impact. Although this value might seem optimistic, measured effectivenesses as high as $97-98 \%$ have been reported for compact counterflow heat exchangers (specially in the context of cryogenic applications), and higher efficiencies can be achieved if a careful design that minimises axial conductivity and flow maldistribution is employed $[43,44,45]$. A $1 \%$ pressure loss is assumed for the working fluid side of all heat exchangers except those rejecting heat to the environment, for which pressure losses are neglected on the grounds that these only require small surface areas. 


\subsection{Implementation}

The cycle model was implemented in Matlab R2016 with thermodynamic properties evaluated using the CoolProp library [46] for each working fluid. Steady state operation is assumed and the charge cycle is operated for a prespecified time, while the discharge cycle is continued until one of the storage tanks is completely discharged. (In fact, all tanks are depleted simultaneously if the mass flows are balanced correctly.) The outcomes from the charge and discharge cycles are then used to compute relevant parameters, such as round-trip efficiency and energy density. In interpreting round-trip efficiencies it is important to note that some sources of loss have not been taken into account. The main omissions are (i) storage (i.e., heat leakage) losses from the reservoirs; (ii) mechanical and electrical conversion losses; (iii) pumping losses for the liquid storage media.

\section{Results and discussion}

\subsection{Selection of operating conditions}

In order to determine the best overall pressure ratios, a parametric study of the combined cycle was performed, the results of which are presented in Fig. 5. The LAES pressure ratio was varied from 100 bar to 300 bar, whilst that for PTES was automatically adapted to obtain specified liquid air temperatures, $T_{L A}$. In the plots shown, three curves are presented according to three different $T_{L A}$ values: low (60 K - i.e., just above the triple point for air), medium $(70 \mathrm{~K})$ and high $(78.5 \mathrm{~K}$ - i.e., just below the boiling point at ambient pressure).

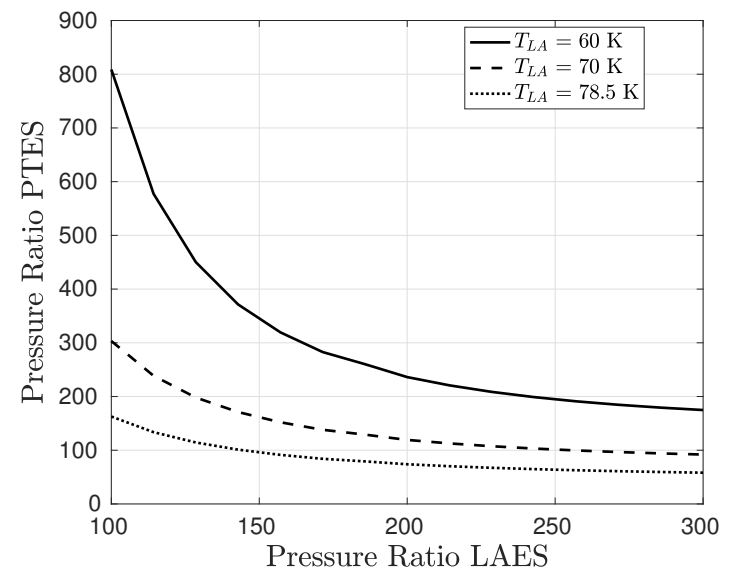

(a)

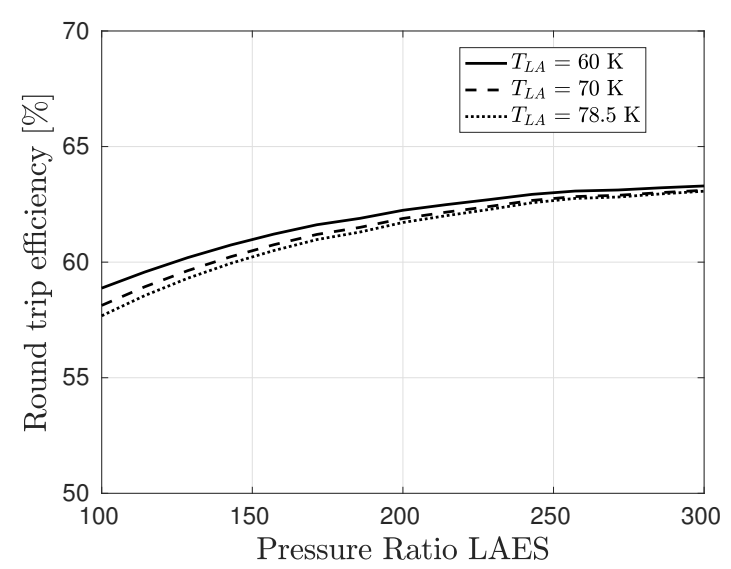

(c)

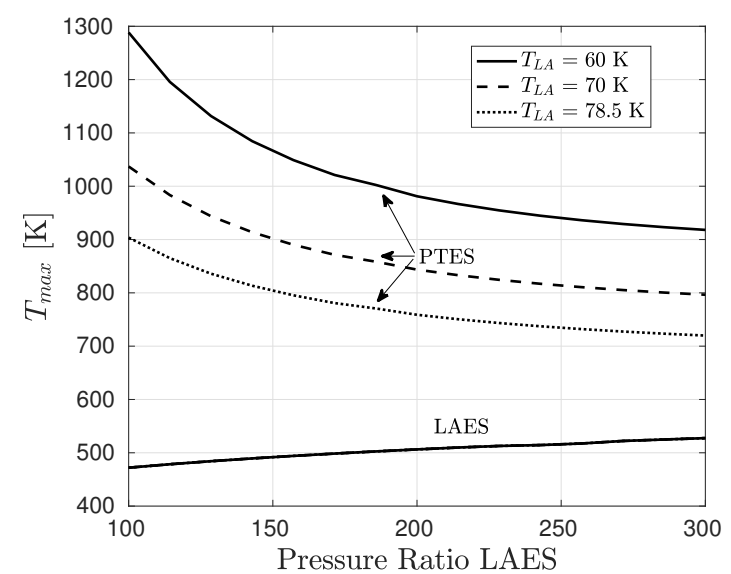

(b)

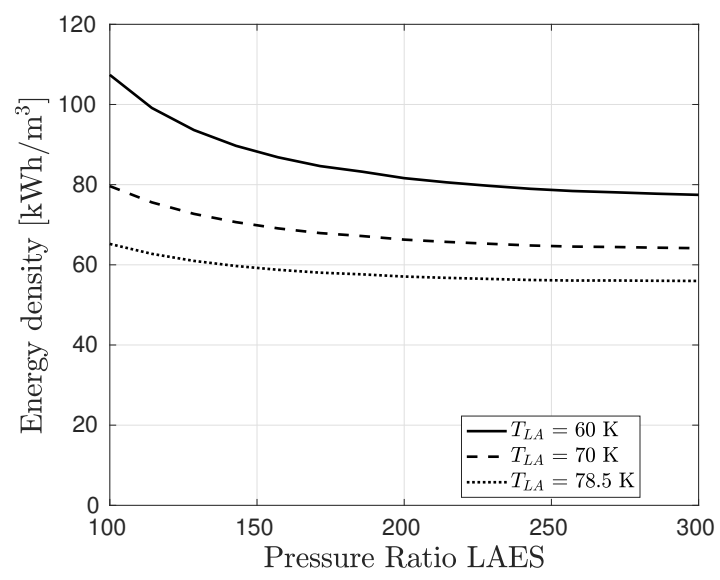

(d)

Figure 5: Parametric study of the combined cycle: $\eta_{c}=\eta_{e}=0.9, \varepsilon=0.97$.

As the overall pressure ratio of the LAES cycle, $\mathrm{PR}_{\mathrm{LAES}}$, increases, that of the PTES cycle, PRPTES, decreases (see Fig. 5a). The dependence is particularly strong for low values of $\mathrm{PR}_{\mathrm{LAES}}$ but then falls off due to the less severe variations in $c_{p}$ of supercritical air at higher pressures, as explained in section 2.4. Low liquid air temperatures require a higher PRPTES so that the helium is sufficiently cold after expansion. While PR $\mathrm{LAES}_{\mathrm{L}}$ corresponds to the top pressure of the LAES cycle (assuming atmospheric pressure is $\sim 1$ bar), this may not be the 
case for the PTES cycle since, as noted above, there is potentially a cost advantage to pressurising this (closed) cycle. Maximum temperatures for the two sub-cycles are shown in Figure 5b, from which it is apparent that a combination of low $\mathrm{PR}_{\mathrm{LAES}}$ and low liquid air temperature leads to impractically high top temperatures in the helium circuit.

Figure $5 \mathrm{c}$ shows that the round-trip efficiency of the combined cycle increases with $\mathrm{PR}_{\mathrm{LAES}}$. This again stems from the temperature dependence of $c_{p}$ for supercritical air, which is smaller at higher pressure and thus allows better performance of the coupling heat exchanger. The efficiency is, however, almost independent of $T_{L A}$ except at low LAES pressure ratio. This is due to two conflicting factors which tend to cancel one another: at low $T_{L A}$

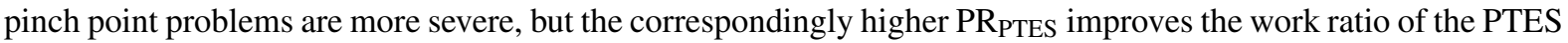
system.

Finally in this section, Figure 5d shows variations of the overall energy density, defined here as

$$
\rho_{E}=\frac{W_{\text {dis. }}}{\sum V_{\text {sto. }}}
$$

where $W_{\text {dis. }}$ is the work returned during discharge and the summation is for the volume of all storage tanks (molten salt, mineral oil and liquid air). The energy density (or rather its inverse) may be used to provide a preliminary indication of the capital cost per unit of stored energy since the cost of storage material, insulation and containment, and the space requirements will all decrease with increasing $\rho_{E}$. (Note that overall storage costs are often broken down into a cost per $\mathrm{kWh}$ energy capacity and a cost per $\mathrm{kW}$ power capacity.)

As shown in the figure, $\rho_{E}$ exhibits the opposite trend to that of efficiency in that it decreases with PR $\mathrm{LAES}_{\mathrm{L}}$

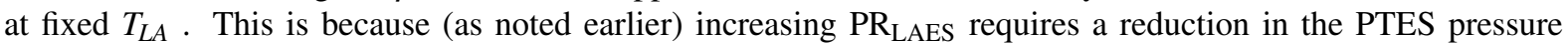
ratio, which in turn reduces the temperature and exergy density of the PTES storage media. Since the PTES plant

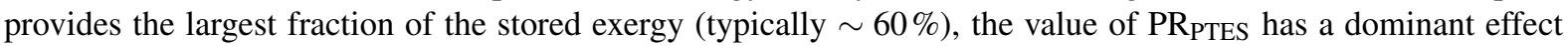
on the overall energy density. This also means that $\rho_{E}$ increases with decreasing $T_{L A}$, as shown by the different curves in Fig. 5 d.

On the basis of the foregoing, a baseline design is proposed with a top LAES pressure of 150 bar and liquid air temperature of $73 \mathrm{~K}$. The maximum PTES temperature is then about $870 \mathrm{~K}$, thereby avoiding high-temperature materials problems and excessive cost. Even so, the overall pressure ratio of the PTES cycle is 135:1, requiring two compressors, each with around 12:1 pressure ratio. This would entail many rotor-stator stages (or very high blade speeds) if accomplished by turbomachinery due to the high value of $c_{p}$ for helium, and it may be preferable to undertake some of the compression (and expansion) with positive displacement devices. Alternatively, neon could be used in place of helium as the working fluid, or the LAES pressure ratio could be raised. (In respect of the latter, the authors in Ref. [47] specify a pressure limit of 250 bar based on published values for supercritical steam plant.) Ultimately, the best choices require a full thermo-economic optimisation, but this is beyond the scope of the present study.

\subsection{Loss distribution}

Having established the baseline operating conditions, a second law analysis is applied to the combined cycle to determine the distribution of exergetic losses. The "lost work" due to irreversibility within the $i$-th component (i.e., heat exchanger, compressor etc.) is given by

$$
W_{L, i r r}^{i}=T_{0} \Delta S_{i r r}^{i}
$$

where $\Delta S_{i r r}^{i}$ is the entropy generated by irreversibility. Additional lost work terms, $W_{L, Q}^{i}$, are incurred if there is heat rejection to the environment from a component at a temperature above $T_{0}$. These are computed in the normal fashion as the product of the heat rejected and the hypothetical Carnot efficiency with which it could have been converted to work. Together these losses relate to the round-trip efficiency through

$$
\chi=1-\frac{\sum\left(W_{L, i r r}^{i}+W_{L, Q}^{i}\right)}{W_{\text {chg }}}
$$

where $W_{\text {chg }}$ is the net work input during charge. Efficiencies computed in this manner tally with values found through a First Law approach, thereby providing a check on the consistency of the cycle model.

Fig. 6 shows the distribution of exergetic losses in the baseline cycle. The biggest losses occur in: (i) the compression and expansion machinery of the PTES sub-cycle; (ii) the main heat exchanger linking the cycles and (iii) heat rejection above ambient temperature (at around $200^{\circ} \mathrm{C}$ ) from the PTES system during discharge. This last loss could be reduced by an additional bottoming cycle (e.g., based on an ORC) at the expense of additional complexity and capital cost. Alternatively the rejected heat might be exploited for other purposes. 


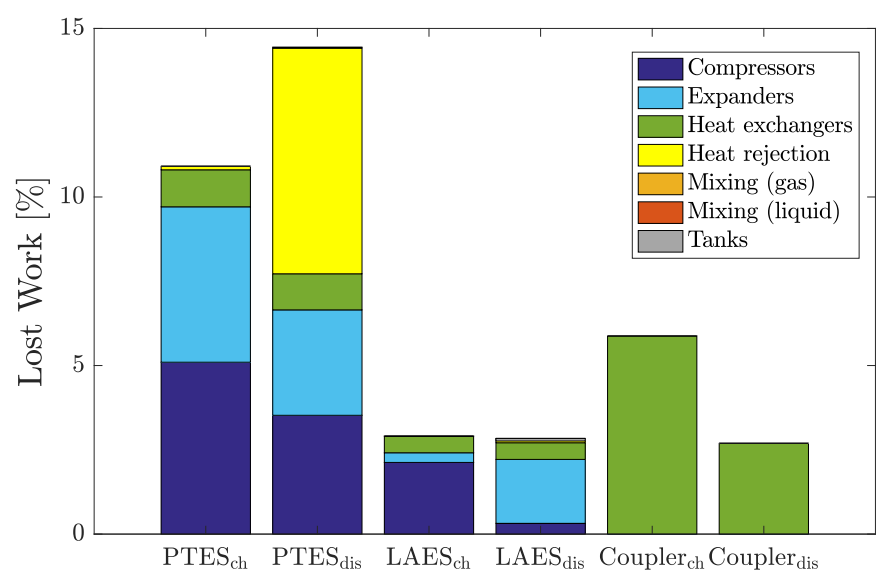

Figure 6: Distribution of exergetic losses for the baseline configuration $\left(\mathrm{PR}_{\mathrm{LAES}}=150, T_{L A}=73 \mathrm{~K}\right)$. Shown as a fraction of the net work input during charge.

Since each gas stream follows a unique path, there is no gas mixing. However, mixing losses would occur in the liquid streams if these were to enter a tank at a different temperature. These losses are avoided in the cycles considered here by using the same pressure ratio for each stage of compression/expansion. Likewise, losses that would occur due to the tanks not being fully discharged are avoided by using the same mass flow ratios (i.e., between air, helium and storage liquids) for charge and discharge. Finally, as already noted, the losses associated with the cryogenic expander and the corresponding liquid air pump are small due to the small work transfers for these devices.

\subsection{Comparison with stand-alone cycles}

The stand-alone systems used for comparison are those presented in Fig. 1, operated under the assumptions discussed in section 3 which are, as far as possible, the same as those for the combined cycle. These are summarised in Table 3a.

The main difference between the PTES plants within the stand-alone and combined cycles (see Fig. 1a and Fig. 2b) is that in the former it has only one compression stage followed by cooling and regeneration, whereas in the latter it has two compression stages followed by cooling, but no regeneration.

In the case of the stand-alone LAES plant (see Fig. 1b), the supercritical air is cooled by two heat exchangers connected in series to two double-tank liquid reservoirs containing methanol and propane, similarly to the system described by Guizzi et al [17]. For the system to be stable over several cycles, each of the storage liquids must be returned to the same temperature after each complete charge-discharge cycle. However, for stand-alone LAES not all the air is liquefied during charge and the flash gas is thus recirculated. Although this contributes to the cooling of the incoming air, the specific heat capacity of the flash gas is much lower than that of supercritical air and consequently the cooling required during charge is greater than that supplied during discharge. This difficulty is resolved by adjusting the ratio of mass flow rates between the air and cooling fluids during the discharge cycle. This enables the cold thermal storage to be fully re-charged, at the expense of slightly greater heat transfer irreversibility. Another difference with respect to the LAES sub-system in the combined cycle is that, while all compressors and expanders are assumed to have the same polytropic efficiency in both systems, a more conservative value $(\eta=0.70)$ is taken for the cryo-expander of the stand-alone LAES cycle. This is in line with the study in [17], and justified due to the complex conditions (two-phase flow with very low vapour quality) at which this particular component operates.

The results of the comparative study are summarised in Table $3 \mathrm{~b}$. The efficiency of the combined cycle is around $60 \%$, similar to that of both PTES and LAES. The table also highlights that the combined cycle gives a significant improvement in energy density, exceeding that of PTES by about $43 \%$ and more than doubling that of LAES.

It should be noted that, due to the difficulties associated with operating expanders in the two-phase region, practical (stand-alone) LAES might employ a throttle instead of a mechanical expander, and in this case the efficiency would fall dramatically, by more than $20 \%$, due to the reduced liquid air yield during charge. For comparison, were a throttle to be employed in the combined cycle it would incur a much smaller efficiency penalty of just $3 \%$. This is because conditions downstream of the throttle remain in the fully liquid state for the combined cycle case. 
Table 3: Nominal case parameters and results

(a) Summary of nominal case parameters for the comparative study. ${ }^{\dagger}$ For all compressors and expanders except the two-phase expander of the stand-alone LAES cycle, in which case $\eta=0.7$

\begin{tabular}{|l|c|c|c|}
\hline Parameter & Single PTES & Single LAES & Combined Cycle \\
\hline Single stage pressure ratio (charge) & 11.6 & 5.3 & 11.6 (PTES), 5.3 (LAES) \\
\hline Number of compression + cooling stages & 1 & 3 & 2 (PTES), 3 (LAES) \\
\hline Overall pressure ratio & 11.6 & 150 & 135 (PTES), 150 (LAES) \\
\hline Polytropic efficiency, $\eta$ & \multicolumn{3}{|c|}{$0.90^{\dagger}$} \\
\hline HEX effectiveness, $\varepsilon$ & \multicolumn{3}{|c|}{0.97} \\
\hline HEX fractional pressure drop, $\Delta p / p$ & \multicolumn{3}{|c|}{0.01} \\
\hline
\end{tabular}

(b) Comparison between the stand-alone and the combined cycles. The specific work refers to the discharge power output per unit mass flow rate. The work ratio is the ratio between power output of the turbines and power input of the compressors/pumps during discharge. In the combined cycle, the ratio of mass flow rates is: $\dot{m}_{\text {air }} \simeq 2.9 \dot{m}_{H e}$. Per unit mass flow rate of helium. ${ }^{* *}$ Per unit mass flow rate of air.

\begin{tabular}{|l|l|c|c|c|}
\hline Parameter & Unit & Single PTES & Single LAES & Combined Cycle \\
\hline Efficiency & {$[\%]$} & $\mathbf{6 1 . 8}$ & $\mathbf{6 1 . 0}$ & $\mathbf{6 0 . 4}$ \\
\hline Energy density & {$\left[\mathrm{kWh} / \mathrm{m}^{3}\right]$} & $\mathbf{4 5 . 9}$ & $\mathbf{2 7 . 4}$ & $\mathbf{6 5 . 7}$ \\
\hline Work ratio (dis) & {$[-]$} & 3.3 & 27.3 & $2.64(\mathrm{PTES})$ \\
\hline Specific work (dis) & {$[\mathrm{MW} /(\mathrm{kg} / \mathrm{s})]$} & $1.44^{*}$ & $0.49^{* *}$ & $\begin{array}{c}0.85^{* *}(\mathrm{PTES}) \\
0.50^{* *}(\mathrm{LAES})\end{array}$ \\
\hline Volume Solar Salt & {$\left[\mathrm{m}^{3} / \mathrm{MWh}\right]$} & 4.5 & - & 3.3 \\
\hline Volume Mineral Oil & {$\left[\mathrm{m}^{3} / \mathrm{MWh}\right]$} & 6.5 & 11.6 & 9.0 \\
\hline Volume Methanol & {$\left[\mathrm{m}^{3} / \mathrm{MWh}\right]$} & - & 5.3 & - \\
\hline Volume Propane & {$\left[\mathrm{m}^{3} / \mathrm{MWh}\right]$} & 10.8 & 11.2 & - \\
\hline Volume Liquid Air & {$\left[\mathrm{m}^{3} / \mathrm{MWh}\right]$} & - & 8.3 & 3.0 \\
\hline
\end{tabular}

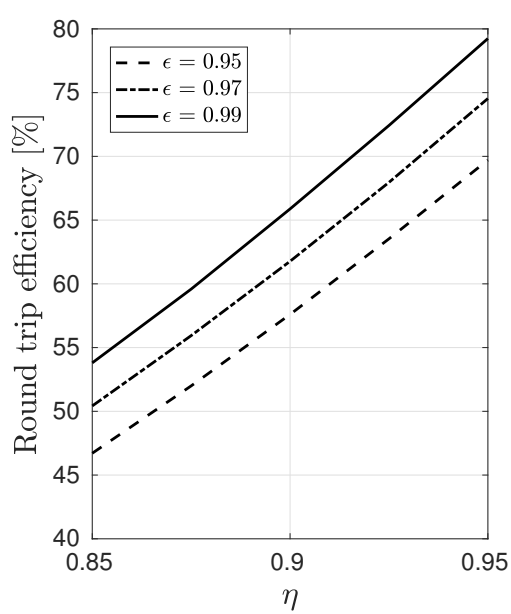

(a) Stand-alone PTES

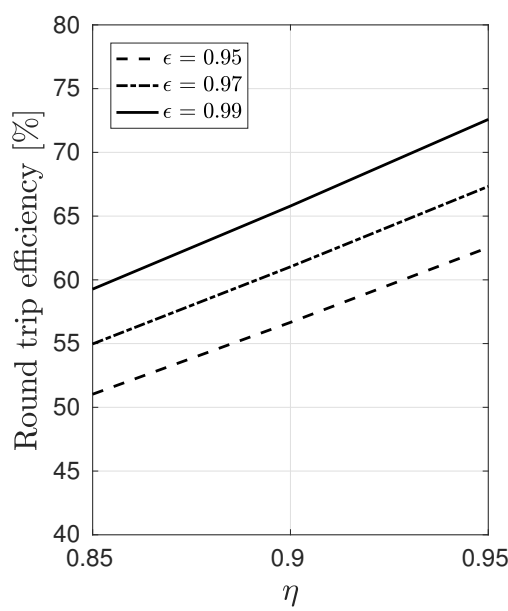

(b) Stand-alone LAES

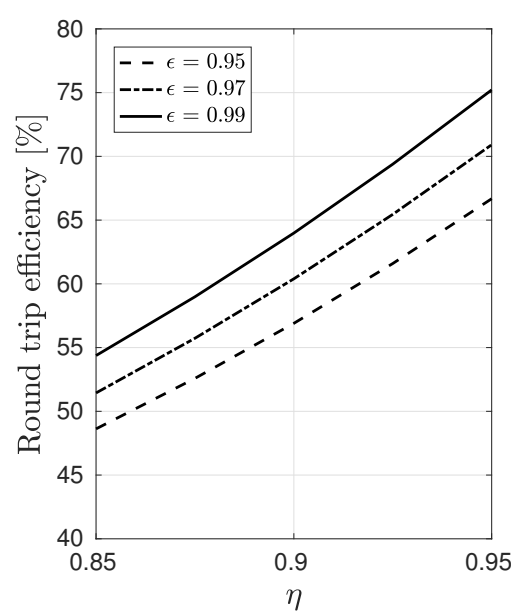

(c) Combined Cycle

Figure 7: Sensitivity study.

\subsection{Sensitivity to loss parameters}

Results thus far have been obtained with fixed values of compression and expansion polytropic efficiencies $(\eta)$ and heat exchanger effectivenesses $(\varepsilon)$. The effect of varying these parameters is shown in Figure 7 . It is notable that the stand-alone LAES is the least sensitive to variations in $\eta$, this being due to its high work ratio, whereas the combined cycle is the least sensitive to variations in $\varepsilon$, due to heat transfer irreversibility being dominated by the pinch point in the coupler. Conclusions regarding the relative merits of the different systems are, however, unaffected by the values of $\eta$ and $\varepsilon$. 


\section{Potential improvements of the combined cycle}

The basic combined cycle as described above may be modified in many different ways with the aim of improving either the efficiency or the energy and power densities. We consider here three such modifications, the results of which are summarised in Fig. 8.

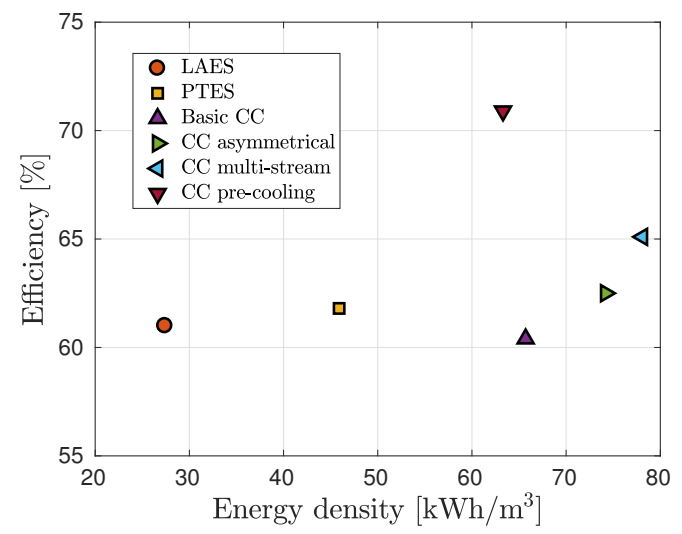

Figure 8: Efficiency and energy density of the different cycles studied.

\subsection{Asymmetrical LAES stages}

In a normal air liquefaction plant, the aim is often to minimise the compression work and this can be achieved by the use of multiple, intercooled stages. Such a strategy is also worth pursuing for a LAES plant if it has access to a low-grade heat source - for example, the waste heat from a thermal power plant. If this is not the case, however, and the "heat of compression" is to be stored (as in the systems described above), then the correct approach should be to maximise the compression work as this will result in higher energy and power density. For a given pressure ratio, the work input will be maximised if a single, adiabatic compression is employed, but the resulting air temperature will be too high for this to be practicable. A reasonable compromise is to use two compression stages but with an asymmetric pressure ratio split, as shown in Fig. 9, such that the temperature after the first stage is $870 \mathrm{~K}$ (i.e., at the Solar Salt limit) and after the second stage is about $500 \mathrm{~K}$. The round-trip efficiency for the combined cycle with this modification is improved slightly to $62.5 \%$ and the overall energy density boosted to $74.2 \mathrm{kWh} / \mathrm{m}^{3}$.

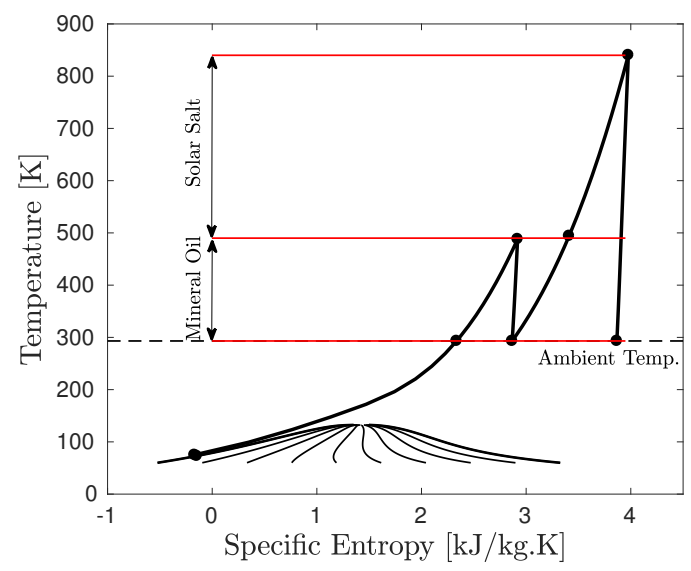

Figure 9: T-s diagram of the LAES subsystem employing two asymmetrical compression stages. The thermal energy released after the first stage is stored in Solar Salt and mineral oil tanks, while the second one only uses mineral oil.

\subsection{Multi-stream heat exchanger}

As previously shown in Figure 6, the main heat exchanger linking the PTES and LAES cycles is one of the biggest sources of irreversibility, typically causing around $20 \%$ of the total loss. This is essentially due to the pinch point 
issues described in section 2.4. One way to reduce the associated loss is to employ a multi-stream heat exchanger that has two levels of helium mass flow so as to more closely match the values of $\dot{m} c_{p}$ for the hot and cold streams. The resulting plant structure is more complex than before, but the main features of the modified system are as follows (see Fig. 11 for the layouts and T-s diagrams). During charge (Fig. 11a), secondary streams of helium are extracted from part way through the second compression (point 1s) and part way through the coupling heat exchanger (point $4 \mathrm{~s}$ ). Heat is recuperated between these streams from points $2 \mathrm{~s}$ to $3 \mathrm{~s}$ and points $4 \mathrm{~s}$ to $5 \mathrm{~s}$ respectively. The coupling heat exchanger thus has two different helium mass flow sections which allows better integration with the air stream, as shown in Fig. 10. The net result is that, for a given helium inlet temperature (point 6), the air is now cooled to a lower exit temperature, implying that less exergy is destroyed and more transferred to the liquid air storage tank. This effect is sufficiently pronounced that with the same operating conditions as those of the original combined cycle the air temperature would drop below the triple point after expansion and thus freeze. The overall pressure ratio of the PTES cycle is therefore reduced so that $T_{L A}$ remains above $60 \mathrm{~K}$. Similar modifications are made for the discharge cycle (Fig. 11b), but due to the lower pressure ratio during discharge there is only one expansion stage for the secondary helium flow, contrasting with the two compression stages during charge.
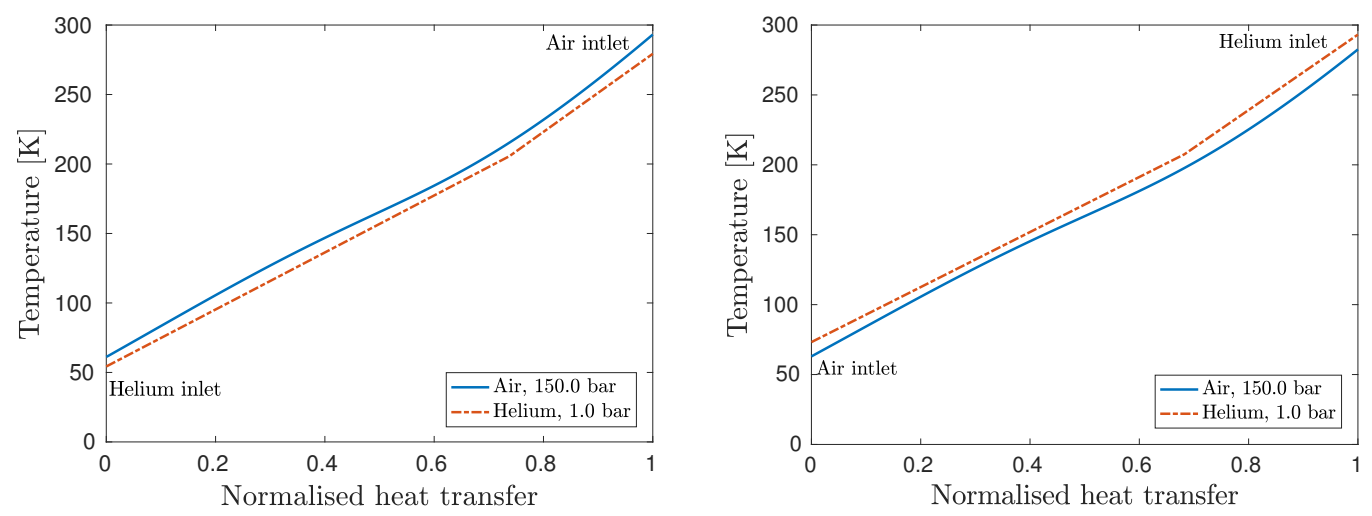

Figure 10: Temperature distribution inside the multi-stream coupler during charge (left) and during discharge (right).

The modified cycle has more degrees of freedom than the original one in that, in addition to the discharge pressure ratio of the PTES subsystem, the following parameters must also be specified: the fraction of mass flow in the secondary helium stream; the pressure ratios for the secondary stream during both charge and discharge and the ratio between the mass flow of air and the total mass flow of helium. These parameters were chosen by optimising for round-trip efficiency using a constrained, non-linear, multi-variable optimisation algorithm, which is based on the interior point method [48] and is readily available in Matlab R2016. When the optimised values are employed, the hot and cold streams of the coupling heat exchanger match much better than in the original cycle (contrast Fig. 10 with Fig. 4) and, in conjunction with the asymmetric compression stage, a round-trip of efficiency of $65.1 \%$ is achieved at an energy density of $78.1 \mathrm{kWh} / \mathrm{m}^{3}$. 


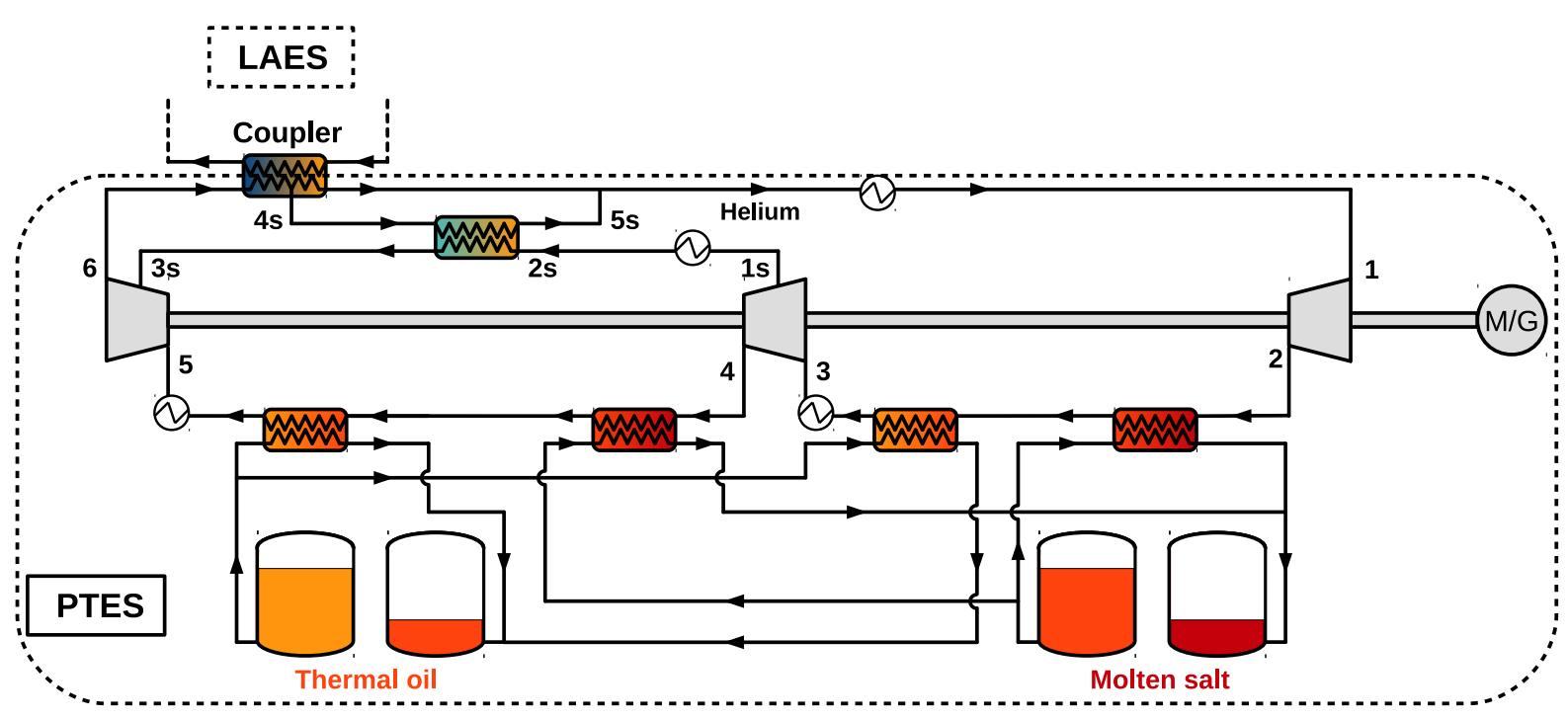

(a) Plant layout (charge).

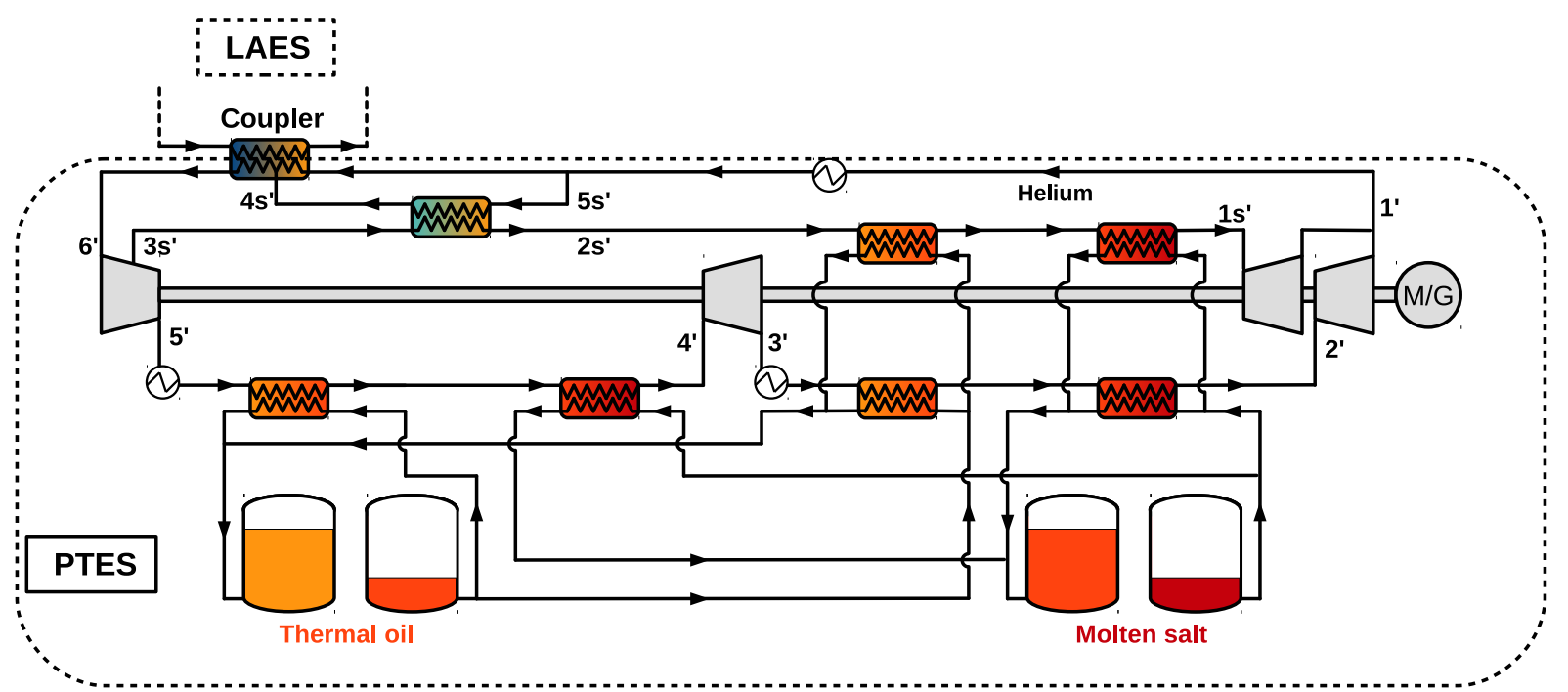

(b) Plant layout (discharge).
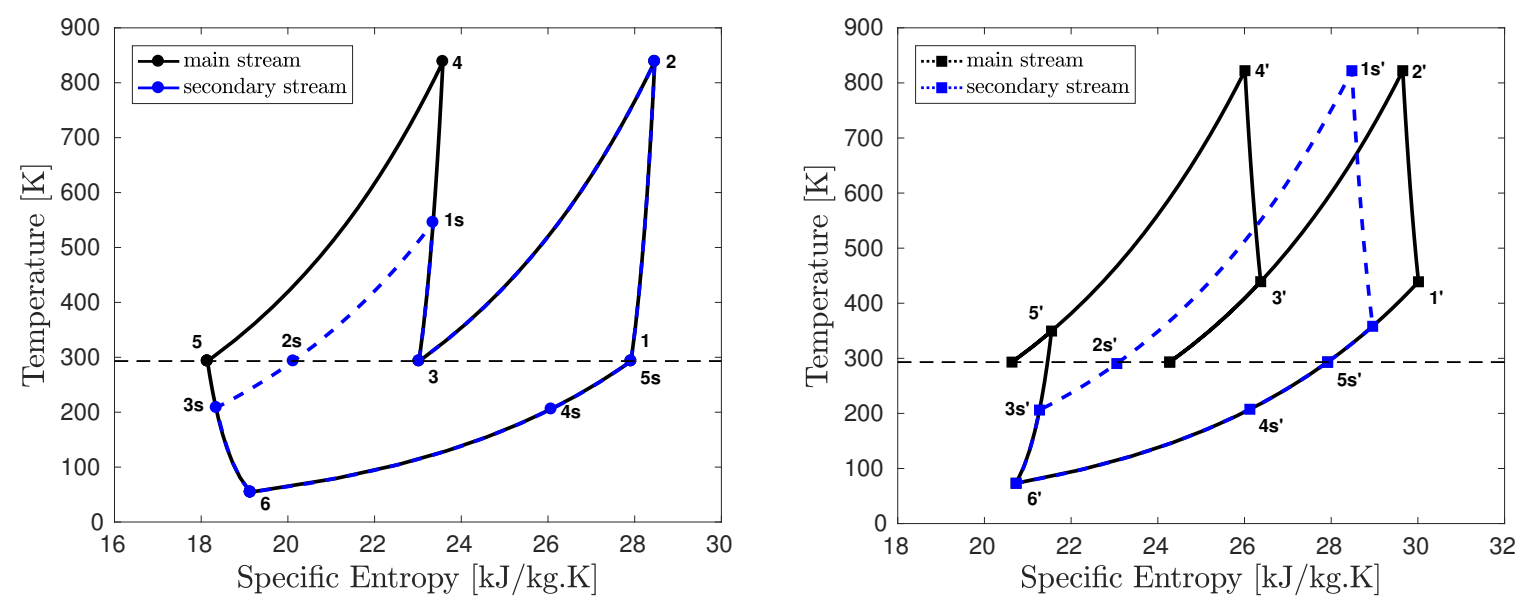

(c) T-s diagrams of the PTES subsystem. Left: charge. Right: discharge.

Figure 11: Adaptation of the combined cycle to allow different levels of helium mass flow rate at two different sections of the coupler. The layout of the LAES subsystem is like that of Figure 2 but employing the asymmetrical compression and cooling stages described in section 5.1. An "s" after a number denotes de secondary stream. Primes $\left({ }^{\prime}\right)$ refer to conditions during discharge. 


\begin{tabular}{|l|c|c|c|}
\hline Parameter & PTES subsystem & LAES subsystem & Combined Cycle \\
\hline \hline Net work input, charge (MWh) & 475 & 180 & 655 \\
\hline Net work output, discharge (MWh) & 250 & 146 & 396 \\
\hline Efficiency (\%) & $\mathbf{5 2 . 6}$ & $\mathbf{8 0 . 9}$ & $\mathbf{6 0 . 4}$ \\
\hline
\end{tabular}

(a) Baseline combined cycle.

\begin{tabular}{|l|c|c|c|}
\hline Parameter & PTES subsystem & LAES subsystem & Combined Cycle \\
\hline \hline Net work input, charge $(\mathrm{MWh})$ & 246 & 194 & 440 \\
\hline Net work output, discharge $(\mathrm{MWh})$ & 150 & 162 & 312 \\
\hline Efficiency $(\%)$ & $\mathbf{6 0 . 9}$ & $\mathbf{8 3 . 6}$ & $\mathbf{7 0 . 9}$ \\
\hline
\end{tabular}

(b) Combined cycle with helium regeneration and supercritical air pre-cooling, also employing the asymmetrical compression and cooling stages described in section 5.1.

Table 4: Main work transfers of each subsystem and the overall combined cycle.

\subsection{Supercritical air pre-cooling}

Table 4a shows the main work transfers for the unmodified combined cycle and its sub-systems. Note that the calculations are undertaken on a specific (per unit mass flow) basis and so the figures shown in the table are for an arbitrary helium mass flow rate of $10 \mathrm{~kg} / \mathrm{s}$ and for a charge (and discharge) time of $10 \mathrm{~h}$ at constant power. The tabulated figures show how the apparent efficiency of the LAES system is much higher than that of the PTES. The main reasons for this are that (a) the LAES cycle has a much higher work ratio (see Table $3 b$ ) and (b) the irreversibility within the coupling heat exchanger manifests itself in the PTES sub-system. (This is because the air essentially retraces the same state path during charge and discharge, whereas the helium must be colder than the air during charge, but hotter than it during discharge.) It is also notable that the efficiency of the combined cycle is weighted more towards that of the PTES sub-system due to the larger work exchanges of the latter. These observations suggest that the overall cycle efficiency can be improved by raising the efficiency of the PTES subcycle and reducing its share of the work input and output. This is achieved here by use of a regenerative helium cycle, with just one (rather than two) compression stages (see Fig. 12a). The regenerator means that the main helium-to-air heat exchanger operates over a narrower temperature range and so some pre-cooling of the air (i.e., by cold recycling) is required to compensate for this. The net result is that the efficiency increase is obtained at the expense of lower energy density.

A number of common alcohols and hydrocarbons are suitable as storage media for the pre-cooling phase, including ethanol, methanol and pentane. Ethanol has been used to generate the results presented here. As with the main coupling heat exchange process, incompatible temperature dependence of $c_{p}$ for air and ethanol leads to pinch point issues, but these are readily rectified by incorporating an intermediate temperature ethanol tank, thereby allowing two independent ethanol mass flow rates (see Fig. 12c). Finally, an additional small improvement is obtained by introducing a secondary compressor that acts only during discharge and that allows an increase in the discharge pressure ratio and thus rejection of heat at lower temperatures (points 3a' and 3b' of the T-s diagram in Fig. 12b). The main work transfers of the modified cycle are shown in Table $4 \mathrm{~b}$. While the additional ethanol tanks imply a more moderate energy density of $63.3 \mathrm{kWh} / \mathrm{m}^{3}$, a significant increase in round-trip efficiency is achieved, reaching $70.9 \%$. 


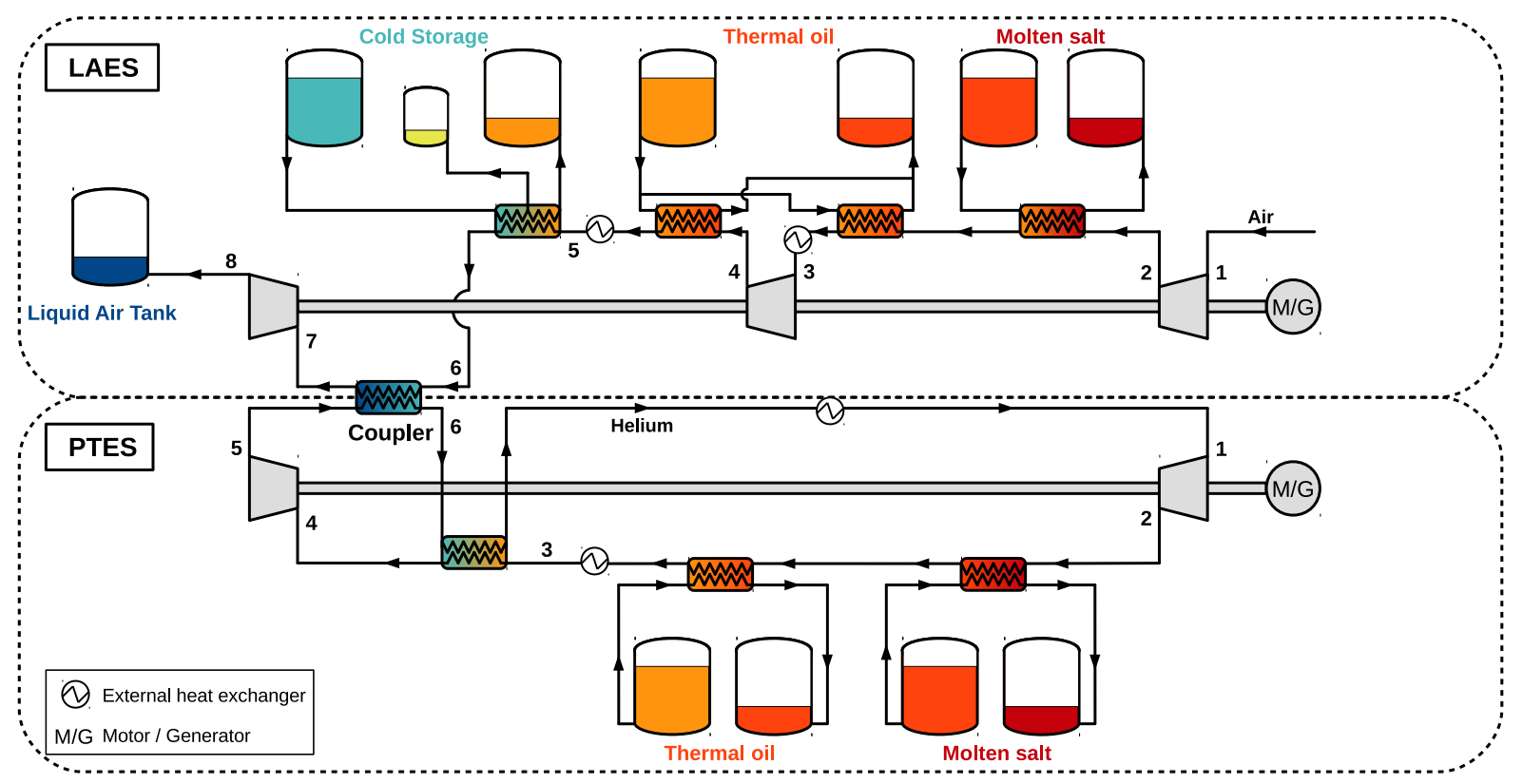

(a) Plant layout.

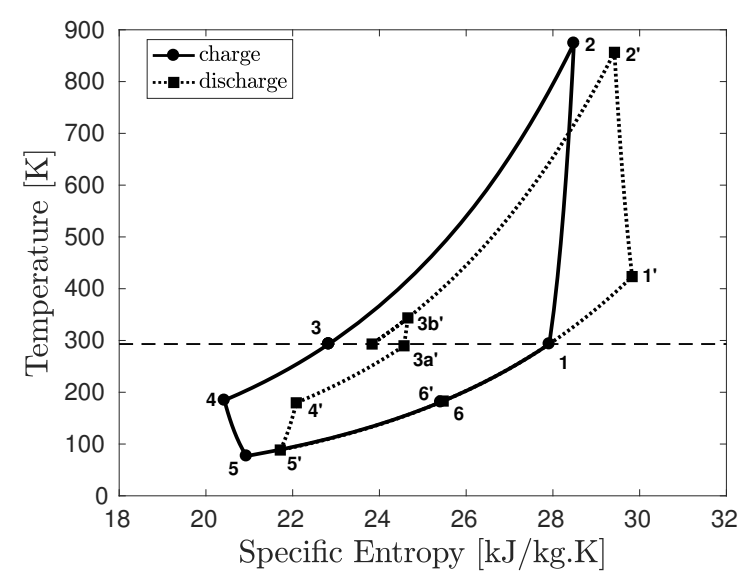

(b) T-s diagrams of the PTES subsystem.

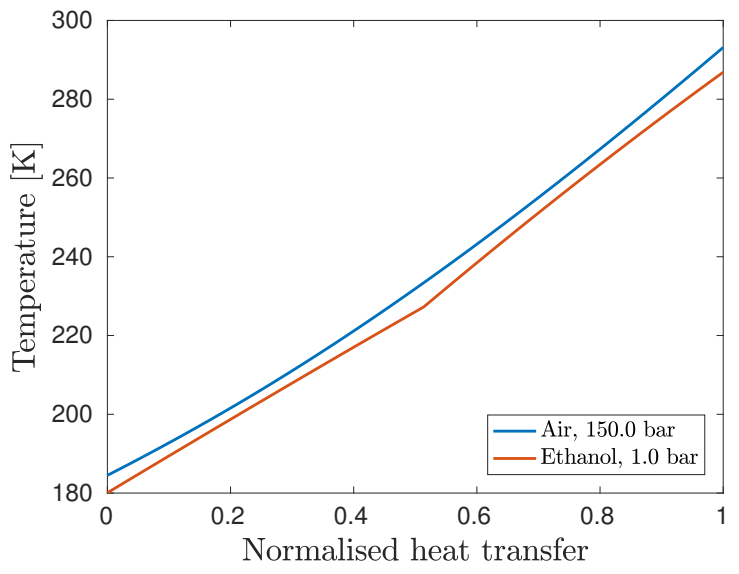

(c) Temperature distribution inside the air-ethanol heat exchanger.

Figure 12: Proposed adaptation of the combined cycle, employing a regenerated PTES cycle and pre-cooling of the supercritical air. (a) Plant layout shown during charge. All processes are reversed during discharge. (b) T-s diagram of the PTES subsystem. Primes $\left(^{\prime}\right)$ refer to conditions during discharge. (c) Temperature distribution in the multi-stream heat exchanger which transfers heat between the supercritical air and the cold storage medium (ethanol), during the pre-cooling phase. 


\section{Concluding Remarks}

The paper has presented a novel thermo-mechanical energy storage system that integrates PTES and LAES into a single combined cycle, employing liquid media as thermal energy storage and helium as a working fluid for the PTES sub-system. Simple, design-level cycle calculations have been undertaken using realistically achievable values of compression and expansion efficiency and heat exchanger effectivenesses, from which the following may be concluded:

1. The baseline combined cycle has a round-trip efficiency which is broadly similar to that of stand-alone PTES and LAES. This is only true, however, under the assumption that cryogenic expanders are practicable when operating with two-phase flow. If a throttle is employed instead, the efficiency of stand-alone LAES falls significantly below that of the other two cycles.

2. A Second Law analysis reveals that the main losses in the baseline combined cycle are due to compression and expansion irreversibility and pinch-point-related losses in the main heat exchanger that links the two cycles. The pinch point arises from the strong variation of specific heat capacity of supercritical air at temperatures and pressures which are close to its critical point. This effect is reduced when operating the LAES subsystem at higher pressures, which has a positive impact on the efficiency of the overall cycle and also implies that lower pressure ratios are required from the PTES subsystem to produce liquid air at a given temperature.

3. Three adaptations of the baseline combined cycle aimed at improving its performance have been proposed and studied. The first exploits asymmetric compression stages and is the easiest to implement. It is also compatible with the other adaptations. The second focuses on alleviating heat transfer irreversibility by employing a multi-stream heat exchanger with two levels of helium mass flow rate, thereby achieving a moderate increase in round-trip efficiency. The third adaptation, on the other hand, focuses on improving the performance of the PTES subsystem (which is found to be the least efficient) and reducing its weight within the combined cycle. This is done by employing a helium-helium regenerator on the PTES side and an additional thermal storage system to pre-cool the supercritical air before entering the helium-air heat exchanger. At the expense of a relatively small reduction in overall energy density, this adaptation achieves a significant increase in thermodynamic efficiency, of about 10 percent points (from $60 \%$ for the baseline combined cycle and the stand-alone cycles up to about $70 \%$ ).

4. The energy density of all the studied versions of the combined cycle $\left(60 \sim 80 \mathrm{kWh} / \mathrm{m}^{3}\right)$ is significantly greater than either of the constituent sub-systems (around $45 \mathrm{kWh} / \mathrm{m}^{3}$ for stand-alone PTES and $30 \mathrm{kWh} / \mathrm{m}^{3}$ for LAES). The implications for cost are difficult to assess at this stage as neither PTES nor LAES have reached sufficient maturity to provide reliable cost data. Nonetheless, it can be stated with reasonable confidence that should these two technologies reach a stage where they are cost-competitive with each other then a combined system is likely to provide further savings, as less storage media is required for a given energy capacity.

5. Baseline operating conditions with pressure ratios of 150 (LAES) and 135 (PTES) provide temperatures that enable the use of abundant storage materials such as Solar Salt and mineral oil. These pressure ratios are substantially higher than usual values for stand-alone Joule-Brayton-based PTES and could have implications for cost contrary to those just stated. This problem, however, is eradicated with the third cycle adaptation, which employs regeneration and operates at much lower pressure ratio on the PTES side. The top LAES pressure is also higher than that of the Highview pilot plant (150 bar vs. 60 bar), but matches well the expected pressures for commercial plants [18]. Additionally, a range of operating conditions are compatible with the required temperature range of unpressurised liquid air (approx. $60 \mathrm{~K}$ to $78.5 \mathrm{~K}$ ) and a variety of candidate storage materials. 
Nomenclature

\begin{tabular}{|c|c|c|c|c|}
\hline Symbol & Description & Units & Subscript & Description \\
\hline$c_{p}$ & Specific heat at constant pressure & $\mathrm{J} \mathrm{kg}^{-1} \mathrm{~K}^{-1}$ & 0 & Ambient conditions \\
\hline$e$ & Specific exergy & $\mathrm{J} \mathrm{kg}^{-1}$ & air, $\mathrm{He}$ & Air, Helium \\
\hline E & Exergy & $\mathrm{J}$ or Wh & $c, e$ & Compressor, expander \\
\hline$h$ & Specific enthalpy & $\mathrm{J} \mathrm{kg}^{-1}$ & chg, dis & Charge, discharge \\
\hline$\dot{m}$ & Mass flow rate & $\mathrm{kg} \mathrm{s}^{-1}$ & $o p t$ & Optimal \\
\hline$p$ & Pressure & $\mathrm{Pa}$ & $s$ & Secondary stream \\
\hline$\dot{Q}$ & Cumulative heat transfer rate & $\mathrm{W}$ & & \\
\hline$\dot{Q}_{T}$ & Total heat transfer rate & $\mathrm{W}$ & Acronym & Description \\
\hline$s$ & Specific entropy & $\mathrm{J} \mathrm{kg}^{-1} \mathrm{~K}^{-1}$ & CAES & Compressed Air Energy Storage \\
\hline$\dot{S}_{i r r}$ & Entropy generation rate & $\mathrm{W} \mathrm{K}^{-1}$ & CSP & Concentrated Solar Power \\
\hline$T$ & Temperature & $\mathrm{K}$ & $\mathrm{CC}$ & Combined Cycle \\
\hline$v$ & Specific volume & $\mathrm{m}^{3} \mathrm{~kg}^{-1}$ & GT & Gas Turbine \\
\hline$w$ & Specific work & $\mathrm{J} \mathrm{kg}^{-1}$ & LA & Liquid Air \\
\hline$\rho_{E}$ & Energy density & $\mathrm{kWh} \mathrm{m}^{-3}$ & LAES & Liquid Air Energy Storage \\
\hline$\delta$ & Infinitesimal process & & LNG & Liquefied Natural Gas \\
\hline$\varepsilon$ & Heat exchanger effectiveness & & ORC & Organic Rankine Cycle \\
\hline$\eta$ & Polytropic efficiency & & PR & Pressure ratio \\
\hline \multirow[t]{2}{*}{$\chi$} & Round-trip efficiency & & PTES & Pumped Thermal Energy Storage \\
\hline & & & TES & Thermal Energy Storage \\
\hline
\end{tabular}

\section{Acknowledgements}

P. Farres-Antunez gratefully acknowledges Peterhouse for the studentship which is allowing him to develop this research project at Cambridge University Engineering Department.

\section{References}

[1] European Parliament. Directive 2009/28/EC of the European Parliament and of the Council of 23 April 2009. Official Journal of the European Union, 140(16):16-62, 2009.

[2] D.J.C. MacKay. Sustainable Energy - without the hot air. UIT Cambridge, 2008. Available free online from www.withouthotair.com.

[3] H. Chen, T.N. Cong, W. Yang, C. Tan, Y. Li, and Y. Ding. Progress in electrical energy storage system: A critical review. Progress in Natural Science, 19(3):291-312, 2009.

[4] X. Luo, J. Wang, M. Dooner, and J. Clarke. Overview of current development in electrical energy storage technologies and the application potential in power system operation. Applied Energy, 137:511-536, 2015.

[5] Wolf Dieter Steinmann. Thermo-mechanical concepts for bulk energy storage. Renewable and Sustainable Energy Reviews, 75(October 2016):205-219, 2017.

[6] T. Desrues, J. Ruer, P. Marty, and J. F. Fourmigué. A thermal energy storage process for large scale electric applications. Applied Thermal Engineering, 30(5):425-432, 2010.

[7] J. Howes. Concept and development of a pumped heat electricity storage device. Proceedings of the IEEE, 100(2):493-503, 2012.

[8] A.J. White, G. Parks, and C. Markides. Thermodynamic analysis of pumped thermal electricity storage. Applied Thermal Engineering, 53(2):291-298, 2013.

[9] Mehmet Mercangöz, Jaroslav Hemrle, Lilian Kaufmann, Andreas Z'Graggen, and Christian Ohler. Electrothermal energy storage with transcritical CO2 cycles. Energy, 45(1):407-415, 2012.

[10] Matteo Morandin, Mehmet Mercangöz, Jaroslav Hemrle, François Maréchal, and Daniel Favrat. Thermoeconomic design optimization of a thermo-electric energy storage system based on transcritical CO2 cycles. Energy, 58:571-587, 2013.

[11] W. D. Steinmann. The CHEST (Compressed Heat Energy STorage) concept for facility scale thermo mechanical energy storage. Energy, 69:543-552, 2014. 
[12] V. Zipf, A. Neuhäuser, D. Willert, P. Nitz, S. Gschwander, and W. Platzer. High temperature latent heat storage with a screw heat exchanger: Design of prototype. Applied Energy, 109:462-469, 2013.

[13] Harald Pointner, Wolf Dieter Steinmann, and Markus Eck. Introduction of the PCM flux concept for latent heat storage. In Energy Procedia, volume 57, pages 643-652, 2014.

[14] P. Farres-Antunez and A.J. White. Thermodynamic strategies for Pumped Thermal Exergy Storage with liquid reservoirs. UK Energy Storage Conference, 2016. Available from: http://ukenergystorage.co/.

[15] Jaqueline Edge. UK Energy Storage Conference. Johnson Matthey Technology Review, 61(3):222--226, 2017.

[16] Robert B. Laughlin. Pumped thermal grid storage with heat exchange. Journal of Renewable and Sustainable Energy, 9(4):044103, 2017.

[17] Giuseppe Leo Guizzi, Michele Manno, Ludovica Maria Tolomei, and Ruggero Maria Vitali. Thermodynamic analysis of a liquid air energy storage system. Energy, 93:1639-1647, 2015.

[18] Robert Morgan, Stuart Nelmes, Emma Gibson, and Gareth Brett. Liquid air energy storage - Analysis and first results from a pilot scale demonstration plant. Applied Energy, 137:845-853, 2015.

[19] E M Smith. Storage of electrical energy using supercritical liquid air. ARCHIVE: Proceedings of the Institution of Mechanical Engineers 1847-1982 (vols 1-196), 191(1977):289-298, 1977.

[20] Kenji Kishimoto, K Hasegawa, and T Asano. Development of generator of liquid air storage energy system. Mitsubishi Juko Giho, 35:60-63, 1998.

[21] Kooichi Chino and Hidefumi Araki. Evaluation of energy storage method using liquid air. Heat Transfer Asian Research, 29(5):347-357, 2000.

[22] A. Sciacovelli, A. Vecchi, and Y. Ding. Liquid air energy storage (LAES) with packed bed cold thermal storage. From component to system level performance through dynamic modelling. Applied Energy, 190:8498, 2017.

[23] Piotr Krawczyk, Lukasz Szablowski, Krzysztof Badyda, Sotirios Karellas, and Emmanuel Kakaras. Impact of selected parameters on performance of the Adiabatic Liquid Air Energy Storage system. Journal of Power Technologies, 96(4):238-244, 2016.

[24] Yongliang Li, Hui Cao, Shuhao Wang, Yi Jin, Dacheng Li, Xiang Wang, and Yulong Ding. Load shifting of nuclear power plants using cryogenic energy storage technology. Applied Energy, 113:1710-1716, 2014.

[25] Yongliang Li, Xiang Wang, Yi Jin, and Yulong Ding. An integrated solar-cryogen hybrid power system. Renewable energy, 37(1):76-81, 2012.

[26] Bharath Kantharaj, Seamus Garvey, and Andrew Pimm. Compressed air energy storage with liquid air capacity extension. Applied Energy, 157:152-164, 2015.

[27] J.S. Howes and J. Macnaghten. Hybrid energy storage system. GB 2537126 A, 2016.

[28] Miles Abarr, Brendan Geels, Jean Hertzberg, and Lupita D. Montoya. Pumped thermal energy storage and bottoming system part A: Concept and model. Energy, pages 1-12, 2016.

[29] Wolf-Dieter Steinmann, Doerte Laing, and Christian Odenthal. Development of the CellFlux Storage Concept for Sensible Heat. Journal of Solar Energy Engineering, 136(1):011011, 2013.

[30] W.D. Steinmann. Thermal energy storage systems for concentrating solar power (CSP) technology. In Advances in Thermal Energy Storage Systems, chapter 21, pages 511-531. Elsevier Ltd. Knovel, 2015.

[31] K. Vignarooban, Xinhai Xu, A. Arvay, K. Hsu, and A. M. Kannan. Heat transfer fluids for concentrating solar power systems - A review. Applied Energy, 146:383-396, 2015.

[32] A. Gil, M. Medrano, I. Martorell, A. Lázaro, P. Dolado, B. Zalba, and L. Cabeza. State of the art on high temperature thermal energy storage for power generation. Part 1-Concepts, materials and modellization. Renewable and Sustainable Energy Reviews, 14(1):31-55, 2010.

[33] E.W. Lemmon, M.O. McLinden, and D.G. Friend. Thermophysical Properties of Fluid Systems. NIST Chemistry WebBook, NIST Standard Reference Database Number 69, Eds. P.J. Linstrom and W.G. Mallard, National Institute of Standards and Technology, Gaithersburg MD, 20899. http://webbook.nist.gov.

[34] Ashmore Mawire. Performance of Sunflower Oil as a sensible heat storage medium for domestic applications. Journal of Energy Storage, 5:1-9, 2016.

[35] Maria A Grompone. Sunflower Oil. In Vegetable Oils in Food Technology, pages 137-167. Wiley-Blackwell, Oxford, UK, mar 2011. 
[36] A. G. Mozgovoi, V. V. Roshchupkin, S. N. Skovorod'Ko, M. A. Pokrasin, and A. I. Chernov. The Density of Liquid Sodium-Potassium Eutectic. High Temperature, 41(3):340-345, 2003.

[37] D. Fernandes, F. Pitié, G. Cáceres, and J. Baeyens. Thermal energy storage: "How previous findings determine current research priorities". Energy, 39(1):246-257, 2012.

[38] Thomas Bauer, Nicole Pfleger, Nils Breidenbach, Markus Eck, Doerte Laing, and Stefanie Kaesche. Material aspects of Solar Salt for sensible heat storage. Applied Energy, 111:1114-1119, 2013.

[39] Hall Dixon. Fluid Mechanics and Thermodynamics of Turbomachinery (6th Edition). Elsevier, nov 2010.

[40] Everett Hylton and Hans Kimmel. Exducer Turbines, the Optimized Solution for LNG Expanders. In Gastech 2oo2, 2002.

[41] A.J. White. Thermodynamic analysis of the reverse Joule-Brayton cycle heat pump for domestic heating. Applied Energy, 86(11):2443-2450, 2009.

[42] F.P. Incropera, D.P. DeWitt, T.L. Bergman, and A.S. Lavine. Fundamentals of Heat and Mass Transfer. John Wiley and Sons, 6th edition, 2007.

[43] E.D. Marquardt and R. Radebaugh. Compact High Effectiveness Parallel Plate Heat Exchangers. In R.G. Ross, editor, Cryocoolers 12, pages 507-516. Kluwer Academic, 2003.

[44] Seungwhan Baek, Jin Hyuck Kim, Sangkwon Jeong, and Jeheon Jung. Development of highly effective cryogenic printed circuit heat exchanger (PCHE) with low axial conduction. Cryogenics, 52(7-9):366-374, 2012.

[45] Lei Zhou, J S Kapat, L C Chow, and Xiaoyi Li. Design of a High Effectiveness Micro Heat Exchanger for Mars Applications. Technical report, Society of Automotive Engineers, 2000.

[46] I.H. Bell, J. Wronski, S. Quoilin, and V. Lemort. Pure and pseudo-pure fluid thermophysical property evaluation and the open-source thermophysical property library coolprop. Industrial and Engineering Chemistry Research, 53(6):2498-2508, 2014.

[47] Miles Abarr, Jean Hertzberg, and Lupita D. Montoya. Pumped Thermal Energy Storage and Bottoming System Part B: Sensitivity analysis and baseline performance. Energy, 2016.

[48] R. A. Waltz, J. L. Morales, J. Nocedal, and D. Orban. An interior algorithm for nonlinear optimization that combines line search and trust region steps. Mathematical Programming, 107(3):391-408, 2006. 